\title{
2 El MDO en español. Estudios sincrónicos
}

\subsection{Introducción}

El MDO, como se ha explicado en la introducción, es un fenómeno gramatical que determinan no solo los rasgos que definen al propio objeto directo, sino también una serie de factores relacionados con la forma en que el objeto está implicado en el evento. El presente capítulo ofrece una descripción detallada de cuál es la relación que cada uno de los factores implicados mantiene con el MDO. A través de los principales trabajos que se han ocupado del tema, el objetivo es dilucidar, asimismo, cómo se relacionan los distintos factores entre sí para poder entender por qué son estos y no otros los que determinan el fenómeno.

La revisión de la bibliografía previa ha puesto de manifiesto la necesidad de profundizar en el estudio, sobre todo, de los factores verbales y este hecho es, precisamente, el que justifica la realización de esta investigación. La telicidad y la afectación han sufrido cierta «desatención», a pesar de que diversos autores han señalado su importancia para explicar el MDO. Sus respectivos efectos sobre el fenómeno se han explicado con frecuencia de forma intuitiva o a partir de conjuntos de ejemplos muy reducidos; además, dichas explicaciones son a veces difíciles de compatibilizar con aquellas que demuestran por qué intervienen los factores intrínsecos al SN.

La estructura del siguiente apartado (2.2), en el que se lleva a cabo la revisión de la bibliografía más reciente que ha estudiado el MDO, hace un repaso de los distintos factores que influyen en el fenómeno, dedicando especial atención a la telicidad y la afectación.

Posteriormente, para comenzar a entender la motivación de cada factor en el fenómeno, el apartado 2.3 explora las funciones que le han sido atribuidas al marcado. En último lugar, el apartado 2.4 recoge las ideas más destacadas presentadas en el capítulo, prestando especial atención a los aspectos más desatendidos en la bibliografía, con el fin de poder establecer de manera más clara cuáles han de ser las metas de este trabajo.

\subsection{Factores que influyen en el MDO}

El MDO es un fenómeno gramatical que está determinado por un reducido conjunto de factores integrado tanto por las propiedades que definen al objeto directo como por las que establecen cuál es su papel dentro del evento designado por el verbo. No obstante, no en todas las lenguas interviene el mismo número de factores, ni la intensidad con que estos actúan es la misma. 
En lo que al español respecta, los factores a los que se ha recurrido tradicionalmente para explicar el MDO han sido tanto los rasgos semánticos inherentes al propio objeto (animacidad) como sus propiedades discursivo-referenciales (definitud y especificidad). Estos rasgos del SN-objeto no dan cuenta de la totalidad de los casos en los que aparece el marcador preposicional, sin embargo, permiten establecer tres dominios bien diferenciados en el conjunto de los objetos directos atendiendo a la obligación, posibilidad o imposibilidad de que estos aparezcan marcados. Así pues, como puede apreciarse en (12), encontramos, en primer lugar, un conjunto de objetos que exigen el uso del MDO siempre que aparecen (dominio de obligatoriedad); en segundo lugar, un conjunto integrado por aquellos donde el uso del marcado es posible, pero no obligatorio (dominio de posibilidad); y, por último, un grupo de objetos que no pueden presentar la marca preposicional bajo ningún concepto (dominio de imposibilidad) (Laca 1995, 65-66). Los ejemplos de (12) recogen un par de casos correspondientes a cada uno de los tres dominios:

(12) Dominios de uso del MDO

a. Dominio de obligatoriedad

He visto ${ }^{*}($ a) Marcos.

Los vimos ${ }^{*}(a)$ ellos.

b. Dominio de posibilidad

En el hospital buscan (a) un médico.

He visto (a) varios niños.

c. Dominio de imposibilidad

María no encuentra $\left({ }^{\star} a\right)$ compañera.

Luis busca $\left({ }^{\star} a\right)$ piso.

Como puede observarse, el MDO es obligatorio en español con nombres propios de persona y pronombres tónicos, tal como muestra (12a); asimismo, es posible con objetos directos encabezados por determinantes tanto definidos (rozando la obligatoriedad en estos casos) como indefinidos, como ocurre en (12b); y resulta imposible (y quizá este sea el dominio más complicado de delimitar), por ejemplo, con los nombres sin determinante en singular, del mismo tipo que los que aparecen en (12c).

Los factores nominales establecen, por lo tanto, estos tres dominios de aparición del MDO; sin embargo, el uso del marcado no es aleatorio dentro del dominio de posibilidad, sino que atiende a otra serie de factores que son aquellos relativos al papel que desempeña el objeto en el evento. Estos últimos, como ya se ha mencionado antes, no han formado parte de la explicación tradicional del fenómeno $\mathrm{y}$, consecuentemente, no han sido estudiados tan a fondo. 
Por todo ello, en las siguientes secciones de este apartado se presentan los principales estudios que han abordado cada uno de los factores, con el fin de obtener una visión amplia que facilite la tarea de establecer qué relación existe entre ellos y cómo interactúan en lo que se refiere al MDO.

\subsubsection{Animacidad}

La animacidad es un rasgo semántico de las expresiones nominales que hace referencia a una determinada propiedad del referente al que estas designan. Dicha propiedad, de naturaleza extralingüística, ha sido generalmente conceptualizada para el estudio de sus efectos lingüísticos por medio de una escala integrada por las siguientes categorías (Comrie 1989, 185; Yamamoto 1999, 2-3; Aissen 2003):

\section{(13) Escala de animacidad \\ humano > animado > inanimado}

Esta escala, basada en la propuesta original de Silverstein (1976, 176), está formada por las categorías resultantes de las distinciones más comunes que las diferentes lenguas establecen en torno al concepto de animacidad, a saber, la distinción entre entidades animadas e inanimadas y, de forma paralela, la diferenciación entre entidades humanas y no humanas; de hecho, de Swart/de Hoop (2018, 6-7) sostienen que, aunque conceptualmente la animacidad pueda ser una noción gradual, lingüísticamente se trata de un fenómeno que puede ser modelizado en términos de los rasgos binarios [ \pm humano] y [ \pm animado]. De cualquier forma, parece evidente que las manifestaciones lingüísticas de la animacidad en la gramática no reflejan la simple dicotomía basada en el significado literal del término animacidad, que distinguiría entre seres [ \pm vivos], sino el grado de prominencia que las entidades animadas poseen en la comunicación humana.

La mayoría de las lenguas del mundo (si no todas) exhiben algún tipo de efecto de la animacidad y esta presencia generalizada se deriva de la percepción humana del mundo. La perspectiva egocéntrica de los hablantes sitúa la actividad humana en el centro de sus inquietudes y esto queda reflejado en los sistemas lingüísticos, como apunta Dahl en su análisis de la egoforicidad $(2008,143)$.

La animacidad desempeña un papel fundamental en el desarrollo de una amplia serie de fenómenos lingüísticos. Este hecho implica que determinados fenómenos solo tienen lugar en categorías que se encuentran por encima de un determinado punto de corte en la escala presentada en (13) (de Swart/Lamers/ Lestrade 2008, 132). Entre dichos fenómenos es posible señalar la asignación de 
categorías como el género y el número, la capacidad de pronominalización de los SN, el orden oracional o el marcado de caso (Dahl/Fraurud 1996).

Respecto a este último, es decir, el marcado de caso, que es el que nos ocupa, cabe señalar que la animacidad es uno de los factores que lo condicionan en un mayor número de lenguas (Silverstein 1976; Dixon 1994; Croft 2002; Aissen 2003). Los ejemplos de (14) ilustran la diferencia entre un objeto directo animado y otro inanimado en malayalam, lengua dravídica cuyo MDO es considerado unidimensional, lo que significa que está determinado por un solo factor.

(14) Animacidad y MDO en malayalam (Asher/Kumari 1997, 203)

a. Avan oru pafuvine vanni.

él una vaca.Acc comprar.PST

'Él compró una vaca.'

b. Avan pustakam vaayiccu.

él libro leer.PST

'Él leyó un libro.'

Como muestra el contraste, la animacidad restringe el uso del caso acusativo en malayalam. La aparición del sufijo de acusativo - e es posible tan solo con objetos animados (pafuvine 'vaca'). El uso del acusativo con objetos inanimados se documenta solamente en cuentos de hadas, pues se trata de contextos donde se le presuponen al objeto características propias de un ente animado (Egger 2016 apud de Swart/de Hoop 2018, 2).

De la misma forma, la animacidad influye también en el MDO de otras muchas lenguas, como el español (15) o el hindi (16), aunque en estas lenguas no es el único factor que determina el fenómeno. En el caso del español, el marcado preposicional con objetos directos definidos es obligatorio ${ }^{2}$ en el caso de SN con referente humano, mientras que simplemente es optativo con los animados no humanos y no está permitido con la mayor parte de los inanimados. En lo que al hindi respecta, los objetos directos humanos generalmente pueden recibir la marca de acusativo, no siendo este, en cambio, el caso de los inanimados, en los que solo aparece cuando presentan una interpretación específica.

2 A excepción de los objetos directos definidos con lectura no referencial del tipo María busca el hombre ideal. 
(15) Animacidad y MDO en español

a. He visto $e^{*} /$ al abuelo en casa. (humano)

b. He visto a el/al perro en casa. (animado)

c. He visto el/*al libro en casa. (inanimado)

(16) Animacidad y MDO en hindi (Mohanan 1994, 79)

a. ilaa-ne ek ${ }^{*}$ baccaal bacce-ko uthaayaa. (humano)

Ila-ERg un niño.NOM/ niño-ACC levantar-PFV

'Ila levantó a un niño.'

b. ilaa-ne ek haar/ *haar-ko uthaayaa. (inanimado)

Ila-ERG un collar.NOM/ collar-Acc levantar-PFV

'Ila levantó un collar.'

Aunque, como se ha mostrado, la animacidad es el factor que determina de manera exclusiva el MDO en algunas lenguas, lo más común es que este fenómeno sea producto de la acción conjunta de varios factores; por tanto, para abordar la animacidad en toda su complejidad será necesario tener en cuenta una serie de factores que se encuentran estrechamente relacionados con ella. Entre ellos se pueden mencionar los papeles temáticos o las características discursivo-referenciales del SN (definitud/especificidad) (Comrie 1989, 186; Yamamoto 1999, 24). En muchas ocasiones resulta complicado establecer los límites entre estos factores puesto que normalmente suelen actuar de forma conjunta y ello dificulta la tarea de analizarlos de manera independiente.

En lo que al papel temático se refiere, existen fuertes correlaciones entre los distintos grados de animacidad y determinados papeles temáticos (Primus 2012). Van Valin/LaPolla (1997) demuestran que los papeles más agentivos, es decir, aquellos situados hacia el lado del Actor en la escala de Macrorroles, corresponden normalmente a SN con referentes animados o humanos, mientras que dicha tendencia se invierte según se desciende hacia el otro extremo de la escala. Este hecho apunta hacia la correlación entre animacidad y agentividad, aspecto que será desarrollado con mayor amplitud en el apartado 2.2.5.

Respecto a las características discursivo-referenciales del SN, han sido numerosos los autores que han señalado la fuerte conexión que existe entre la animacidad de un referente y el tipo de expresión lingüística utilizado para referirse a él (Silverstein 1976; Dixon 1994; Croft 2002; Aissen 2003). Esta relación es sumamente relevante para la descripción del MDO en numerosas lenguas y, particularmente, en español y, por ello, se describe con más detalle a lo largo del siguiente apartado. 


\subsubsection{Definitud}

La definitud es un rasgo de las expresiones nominales que las caracteriza atendiendo a las relaciones de referencia que establecen con las entidades que designan. No obstante, más allá de esta definición tan genérica, la noción de definitud es una de las que más debate científico ha suscitado desde la aparición de la lingüística, o incluso antes, en el campo de la Filosofía. Tradicionalmente se han catalogado como expresiones definidas los nombres propios, los SN definidos, los demostrativos, los pronombres personales y las construcciones posesivas. Desde un punto de vista preteórico, estas expresiones en singular denotan o hacen referencia de manera inequívoca a un objeto, que es identificable como el único que denota la expresión. Sin embargo, la fijación referencial de una expresión definida está determinada por diferentes factores como el tipo de expresión, determinadas reglas semánticas y ciertas estrategias pragmáticas (von Heusinger 1997, 2). Esta diversidad de factores, junto a los diferentes usos que se realizan de los SN definidos, ha dado pie a la creación de teorías que, enfatizando unos $\mathrm{u}$ otros aspectos, abordan el concepto de definitud desde perspectivas diferentes.

Así pues, las teorías acerca de la definitud se pueden clasificar, a grandes rasgos, en dos bloques, que surgen de dos trabajos ya considerados clásicos en lo que concierne al estudio de la referencia: por un lado, la teoría de Russell (1905), basada en el concepto de unicidad, defiende que el uso de las expresiones definidas implica la existencia de un único referente que puede ser identificado a partir del contenido de la expresión utilizada; y, por otro lado, la teoría de la familiaridad, propuesta por Christophersen (1939), argumenta en contra de la teoría de Russell y sostiene que una expresión definida hace referencia a un elemento familiar o reconocible para los participantes del acto comunicativo. En la línea del primer enfoque, pueden citarse los trabajos de Hawkins (1978), Nearle (1990) o Abbott (2019), entre otros muchos; mientras que, en lo que respecta a la teoría de la familiaridad, se pueden destacar los trabajos de Karttunen (1976), Heim (1982) y Kamp (1981), también entre otros muchos. Por último, resulta interesante destacar también el enfoque planteado por von Heusinger (1997), basado en el trabajo original de Lewis (1979). Esta propuesta destaca por su explicación de la definitud a través de la noción de prominencia, concepto que se utilizará en el capítulo 6 para dar cuenta de la forma en que los diferentes factores actúan sobre el MDO. Pues bien, von Heusinger afirma que las descripciones definidas no solo hacen referencia a un elemento previamente introducido en el discurso, sino que se relacionan con el referente del mismo tipo más prominente hasta el momento. La mayor aportación de este enfoque es la incorporación de la información contextual a la representación de la expresión por medio de una jerarquización de los elementos que contiene el contexto, en lo que al grado de prominencia se refiere. 
Actualmente, la naturaleza exacta de las expresiones definidas continúa siendo objeto de debate, pero dicha polémica excede los límites establecidos a partir de los objetivos de este trabajo. Por ello, de aquí en adelante se adopta la definición, mencionada hacia el comienzo de este apartado, que considera que las expresiones definidas en singular denotan o hacen referencia de manera inequívoca a un objeto, que es identificable como el único que denota la expresión.

En lo que a esta investigación concierne, la definitud de las expresiones nominales constituye un rasgo que ha sido vinculado a numerosos fenómenos de naturaleza semántica, entre los que se puede destacar el MDO. En algunas lenguas que manifiestan este tipo de marcado, la definitud se constituye como el factor que determina en primera instancia dicho fenómeno. Este es el caso del hebreo, donde la preposición 'et es obligatoria con los objetos definidos (incluyendo los inanimados), tal como se muestra en (17a); mientras que con los indefinidos no se utiliza, como puede apreciarse en (17b).

(17) Definitud y MDO en hebreo (Givón 1978 apud Aissen 2003, 453)
a. Ha-seret her'a 'et-ha-milxama.
la-película mostrar.PST ACC-la-guerra
'La película mostraba la guerra.'
b. Ha-seret her'a (*'et-) milxama.
la-película mostrar.PST (ACC-)guerra
'La película mostraba una guerra.'

La obligatoriedad de la preposición en hebreo no se restringe a los SN definidos, sino que se extiende a los pronombres y a los nombres propios, tal como se desprende de la jerarquía de definitud que se muestra en (18). Así, en (19a) el marcado preposicional es obligatorio pues el objeto directo está integrado por un nombre propio/pronombre/SN definido y, por el contrario, su ausencia resulta agramatical, como se comprueba en (19b), dentro del mismo contexto.

(18) Escala de definitud (Comrie 1989; Croft 2002; Aissen 2003) pronombres $>$ nombres propios $>$ SN definidos $>$ SN indefinidos

(19) Definitud y MDO en hebreo (Kagan 2020, 149)
a. pagaSti et dani/ oto/ et ha-yalda. yo.conocer.PST ACC Dani/ él ${ }_{\mathrm{AcC}} /$ ACC la-chica 'Yo conocí a Dani/ Yo lo conocí a él/ Yo conocí a la chica.'
b. *pagaSti dani/ hu/ ha-yalda.

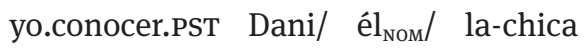
'Yo conocí a Dani/ Yo lo conocí a él/ Yo conocí a la chica.' 
El hecho de que el marcado de una categoría posibilite (u obligue) la aparición de la marca en las categorías superiores evidencia de nuevo, al igual que ocurría con la animacidad, la utilidad de las escalas de prominencia para representar el efecto que ejerce el factor sobre el MDO. Sin embargo, la acción independiente de la definitud como factor desencadenante del marcado no es el caso más común entre las distintas lenguas, sino que estas suelen presentar sistemas de marcado de caso en los que están implicados diversos factores y, sin duda, la interacción más frecuente que tiene lugar es la que se produce entre animacidad y definitud. El hindi (20) o el español (21) son claros ejemplos de lenguas en las que, a pesar de que el factor predominante que desencadena el marcado sea la animacidad, la definitud también desempeña un papel importante. En hindi, la marca de acusativo -ko es obligatoria con todos aquellos objetos que posean un referente humano, como se ha demostrado en (16); sin embargo, con los inanimados se presenta como opcional, siendo posible solo con los objetos definidos. Así, el MDO es opcional con los SN definidos como se comprueba al comparar (20a) y (20b), mientras que no resulta posible asociado a una interpretación indefinida y, por ello, cuando dicha interpretación se hace explícita mediante un determinante, como en el caso de (20c), la aparición de la marca resulta agramatical (Mohanan 1994). En lo que al español se refiere, dentro de la categoría de los objetos directos humanos, que es la categoría fundamental a través de la cual se extiende la marca preposicional, encontramos que esta es obligatoria con los objetos defini$\operatorname{dos}^{3}(21 \mathrm{a})$, mientras que simplemente es posible con los indefinidos (21b).

(20) MDO y definitud en hindi (Mohanan 1994, 87-88)
a. Ravii-ne kaccaa kelaa kaataa.
Ravi-ERG verde plátano cortar.PERF
'Ravi cortó el/un plátano verde (que no estaba maduro).'
$\begin{array}{lll}\text { b. Ravii-ne kacce kele-ko } & \text { kaataa. } \\ \text { Ravi-ERG verde plátano-ACC } & \text { cortar.PERF }\end{array}$
'Ravi cortó el plátano verde (que no estaba maduro).'
c. Ravii-ne ek kaccaa kelaal *kacce kele-ko kaataa. Ravi-ERG un verde plátano/ verde plátano-ACc cortar-PERF 'Ravi cortó un plátano verde (que no estaba maduro).'

3 A excepción de los objetos directos definidos con lectura no referencial del tipo María busca el hombre ideal. 
(21) MDO y definitud en español

a. Luis vio *el/al niño en la calle.

b. Luis vio un/a un niño en la calle.

Animacidad y definitud han sido tradicionalmente los dos rasgos relativos al SN que se han utilizado para explicar el MDO en la mayor parte de las lenguas; sin embargo, estos dos factores no explican la totalidad de los casos de marcado y, de ello, se ha deducido que la interacción de factores es aún más compleja en algunas lenguas y, por lo tanto, el número de factores que intervienen es aún mayor. El siguiente apartado aborda la influencia de la especificidad, cuya relación con la definitud es tan estrecha que en ocasiones se han tratado como un factor único: el de las propiedades referenciales de la expresión que conforma el SN.

\subsubsection{Especificidad}

La especificidad es una noción pragmático-semántica que distingue entre diferentes usos o interpretaciones de los SN indefinidos. Dicha noción está relacionada con la de intención referencial, según la cual el hablante utiliza un SN indefinido específico para referirse a un objeto que «tiene en mente» (von Heusinger 2019, 70). La estrecha relación que la noción de especificidad guarda con la categoría de los SN indefinidos ha dado pie a que muchos autores la engloben dentro del propio factor de la definitud y la incluyan como una extensión de la escala presentada antes en (18) y que recuperamos ya ampliada ahora en (22).

(22) Escala de definitud/especificidad (Aissen 2003, 437)

pronombres personales $>$ nombres propios $>$ SN definidos $>$ SN indefinidos específicos $>\mathrm{SN}$ indefinidos no específicos

El concepto de especificidad fue introducido en los años 60 para dar cuenta de ciertos casos de ambigüedad lógica relacionados con los SN indefinidos como el recogido en el ejemplo de (23). El SN indefinido un noruego puede admitir dos lecturas diferentes en la oración María quiere casarse con un noruego: en una de ellas, la de (23a), el referente del objeto es una persona concreta, cuya existencia se da por hecha y de la que, incluso, es posible conocer la identidad; por otro lado, en (23b) la lectura que se obtiene no hace referencia a ningún individuo en particular, sino simplemente a un potencial referente que cumpla la característica de ser noruego. La primera lectura se corresponde con la interpretación específica, mientras que la segunda sería la no específica (Leonetti 2012, 296). 
(23) Ambigüedad interpretativa de los SN indefinidos

a. María quiere casarse con un noruego (que conoció el año pasado).

b. María quiere casarse con un noruego (pero aún no ha conocido a ninguno).

La explicación clásica para afrontar este tipo de ambigüedades se atribuyó a la cuestión del alcance en semántica formal. Cuando el artículo indefinido, al que se considera como cuantificador, presenta alcance amplio con respecto al verbo intensional, se obtiene la lectura específica, mientras que cuando el alcance relativo se invierte, la lectura que se obtiene es la no específica (Quine 1956).

La investigación que ha abordado la especificidad en las últimas cuatro décadas ha sido extremadamente productiva y son numerosos los acercamientos y las teorías que han sido propuestos para explicar esta noción. El concepto de especificidad se ha extendido a través de distintas disciplinas lingüísticas, ocupando desde la semántica y la sintaxis formal, hasta la tipología funcional, y esta diversidad de enfoques ha provocado una ampliación del conjunto de fenómenos que han sido asociados a la distinción de especificidad y, por tanto, un aumento de los tipos de especificidad que han sido señalados. Von Heusinger (2019, 73-74), que ofrece una visión panorámica del fenómeno, señala hasta nueve tipos de especificidad descritos en la bibliografía previa; sin embargo, defiende que se puede postular una descripción muy básica que subyace a los distintos tipos de especificidad y que se define en términos de «anclaje referencial», en la que el referente de un indefinido específico es funcionalmente dependiente del referente de otra expresión (von Heusinger 2002; 2019).

En cuanto a la forma en la que las diferentes lenguas codifican la especificidad, es distinta de unos casos a otros. Los mecanismos utilizados son muy variados y van desde la utilización de algunos elementos léxicos, a ciertos patrones de entonación o al uso de determinadas configuraciones sintácticas. Entre ellos, se pueden extraer como ejemplos el sistema de artículos del magrebí, los afijos que el ruso utiliza sobre sus pronombres indefinidos o la marca de acusativo en turco; y, en concreto, es en esta última es en la que vamos a centrar nuestra atención a continuación.

El MDO en turco implica la interpretación específica del objeto directo. El turco carece de artículo definido y tan solo posee el artículo indefinido (bir); por lo tanto, cuando el objeto directo aparece sin artículo y acompañado del sufijo de acusativo - $i$, la lectura que se obtiene es definida, como se observa en (24a); por otro lado, si el objeto aparece encabezado por el artículo indefinido y, además, presenta la marca de acusativo, la lectura será de indefinido específico, tal como ocurre en (24b); mientras que si, manteniendo el artículo indefinido, no presenta marca de acusativo, la lectura será de indefinido no específico, como refleja el caso de (24c). Así pues, el sufijo de acusativo o MDO realmente no implica definitud, sino especificidad, pues se puede combinar con el artículo indefinido. 
(24) MDO en turco (von Heusinger/Kornfilt 2005, 7-8)
a. (Ben) kitab-l oku-du-m. (definido) yo libro-Acc leer-PST-1sG
'Leo el libro.'
b. (Ben) bir kitab-l oku-du-m. (indefinido específico) yo un libro-Acc leer-PST-1SG 'Leo un libro (determinado).'
c. (Ben) bir kitap-ø oku-du-m. (indefinido no específico) yo un libro-NOM leer-PST-1SG 'Leo un libro (cualquiera).'

Partiendo de esta base, el turco se ha considerado tradicionalmente como una lengua de MDO unidimensional, determinado, en principio, tan solo por un factor, como ocurría en malayalam con la animacidad; sin embargo, estudios recientes señalan que la unidimensionalidad del marcado no parece ser tan estricta como se postulaba y que también intervienen otros factores como la animacidad (Krause/von Heusinger 2019). Así pues, es frecuente que la especificidad interactúe con otros factores en el uso del MDO, como ocurre en español, lengua en la que dicho factor explica gran parte de la variación en el marcado de los SN indefinidos a la que se hacía referencia en el apartado anterior.

El uso del MDO guarda en español cierta relación con la interpretación específica del objeto directo, aunque dicha relación no es tan directa como ocurre en el caso del turco. López (2012), entre otros autores, defiende que la marca preposicional es compatible, dentro del ámbito de los animados, tanto con la lectura específica del objeto, que es la que recoge (25a), como con la no específica, representada por (25b); por otro lado, la ausencia de la marca solo permite obtener una lectura no específica, pues resulta agramatical en contextos en los que otros mecanismos determinan la lectura específica, como ocurre en (25a), donde la oración de relativo con el verbo en indicativo fija la especificidad del objeto directo.

(25) Especificidad y MDO en español (López 2012, 18)

a. María buscó ${ }^{*}($ a $)$ una gestora que habla alemán.

b. María buscó (a) una gestora que hable alemán.

Así, podría afirmarse que en español el MDO no implica la lectura específica del objeto directo (animado), sino que simplemente la posibilita (Leonetti 2004; 2012; López 2012; 2016). De hecho, se ha demostrado que el español no posee mecanismos gramaticales que codifiquen la especificidad. Aquellos a los cuales se les ha atribuido esta función simplemente codifican otros significados, en su 
mayoría relacionados con la estructura de la información, la modalidad o la prominencia de los argumentos. La especificidad se infiere, por tanto, de manera pragmática de dichos significados, constituyéndose como un epifenómeno de la interacción de distintos factores (Leonetti 2004, 110).

Uno de los factores que con frecuencia ha sido asociado con la especificidad y, al mismo tiempo, con el MDO es la topicalidad. La conexión más directa entre especificidad y topicalidad parte del hecho de que los SN indefinidos en posiciones de tópico tienden a recibir lecturas fuertes (ya sea específicas o genéricas) (Leonetti 2004, 93) y, en lo que al MDO se refiere, las lenguas cuyo marcado depende de la especificidad, como el turco, tienden a marcar de forma obligatoria el objeto directo si aparece topicalizado mediante dislocación (von Heusinger 2019, 104).

\subsubsection{Topicalidad}

Lambrecht $(1994,5)$ define la estructura de la información como el componente de la gramática oracional que sirve para crear proposiciones pragmáticamente estructuradas. Una proposición pragmáticamente estructurada refleja la suposición del hablante sobre el estado de conocimiento del destinatario en el momento en que tiene lugar el enunciado. En la estructura de la información, Lambrecht destaca dos categorías fundamentales: presuposición y aserción. La presuposición pragmática se define como el conjunto de proposiciones que el hablante asume como previamente conocidas por el destinatario, mientras que la aserción es la proposición que se espera que el destinatario conozca como resultado de oír la oración pronunciada (1994, 52). Asimismo, es fundamental la noción de tópico, definida por el autor ya mencionado como el referente sobre el que trata la proposición. Los tópicos son, por tanto, referentes del discurso sobre los que el hablante afirma algo relevante y, generalmente, constituyen información dada, prosódicamente no acentuada, identificable, activada o accesible, definida y que forma parte del ámbito de las presuposiciones.

Entre el conjunto de presuposiciones que evoca el hablante al producir un enunciado, hay que incluir también las conjeturas que este realiza acerca de la relevancia o topicalidad que un determinado referente posee en el discurso, es decir, el grado en que un referente puede ser escogido como centro de interés en ese momento respecto al que una proposición pueda ser interpretada como información relevante $(1994,54)$. No obstante, la función de tópico no tiene por qué ser exclusiva de un solo referente en un enunciado; de hecho, un enunciado puede aportar información sobre más de un referente, como ocurre en las oraciones ditransitivas. En este tipo de casos, Dalrymple/Nikolaeva (2011, 55-59) 
proponen la existencia de dos tópicos: uno primario y otro secundario. El tópico primario sería aquel acerca del cual se construye el enunciado (aboutness topic), mientras que el tópico secundario quedaría definido respecto al tópico primario. De hecho, Nikolaeva $(2001,26)$ define el tópico secundario como «la entidad cuya relación con el tópico primario describe el enunciado».

La topicalidad de un referente está determinada por diversos factores que son los que lo constituyen como un mejor o peor candidato a desempeñar la función de tópico. Entre ellos se pueden señalar la animacidad, la definitud, el papel temático y la función sintáctica (Hawkinson/Hyman 1974; Givón 1976). Dichos factores están estructurados por medio de las escalas recogidas en (26), como ya se ha señalado en los apartados previos para algunos de ellos, e implican que cuanto más elevada sea la posición que ocupa el objeto en cada una de las ellas, mayor será la probabilidad de que desempeñe la función de tópico.

(26) Escalas de topicalidad (Givón 1976, 169)

a. Animacidad: humano $>$ animado $>$ inanimado

b. Definitud: pron. pers. $>$ nombre propio $>$ SN def. $>$ SN ind.

c. Papel temático: agente $>$ dativo/beneficiario $>$ paciente

d. Función sintáctica: sujeto $>$ objeto directo $>$ oblicuo

Numerosos autores han defendido que la topicalidad o el estatus informativo del objeto directo es, precisamente, lo que desencadena el MDO en diversas lenguas. Así, Niculescu $(1959,182)$ ya definía el MDO como una «modalité syntactique obligatoire destinée à marquer l’object direct personnel, individualisé (défini, déterminé) et mis en relief du point de vue stylistique», donde, como señala Iemmolo (2010, 244), stylistique debería ser entendido como pragmático. La idea de que la topicalidad ha de ser considerada como un factor desencadenante del MDO ha sido señalada posteriormente por diversos autores como Laca (1995), Pensado (1995b), Escandell-Vidal (2009), Iemmolo (2010), von Heusinger/Kaiser (2005; 2007), Dalrymple/Nikolaeva (2011) y Melis (2018), entre otros. Estos trabajos, en su mayoría, explotan la idea de la topicalidad como factor explicativo del marcado a propósito de las lenguas románicas y, en concreto, del español.

Laca (1995) defiende que la ventaja de recurrir a la noción de topicalidad para explicar el MDO reside en que es capaz de aunar las distintas teorías explicativas del fenómeno que habían sido propuestas hasta la fecha, a saber, la de analogía con el sujeto (Lenz 1920; Keenan 1975; Roegiest 1979), la de analogía con el dativo (Meyer-Lübke 1899; Dietrich 1987) y la de la individuación (Coseriu 1955; Kliffer 1995; Fernández Ramírez 1951). Esto se debe a que las características que comparten los sujetos, los dativos y los objetos directos marcados ([+humano], [+definido]) son precisamente las que los convierten en tópicos potenciales. 
Pensado (1995b), Iemmolo (2010) y Melis (2018) hacen hincapié en la topicalidad como detonante de la aparición del MDO en español. Estos autores sostienen que el marcado surge en los objetos topicalizados mediante dislocación a la izquierda. Desde dicho contexto, se habría extendido posteriormente al resto de posiciones atendiendo a las escalas de animacidad y definitud (véase apartado 3.2). Los ejemplos de (27) pertenecen al Cantar de Mio Cid (CMC) y reflejan el momento en que los SN léxicos con función de objeto tan solo recibían el marcado en posición topicalizada.

(27) MDO en El Cantar de Mio Cid (Melis 1995, 138-139)

a. Alas sus fijas enbraço las prendia.

b. Mas cuando sacaron mis fijas de Valençia la mayor.

Iemmolo (2010) va incluso más allá y defiende que este proceso de creación del MDO, en el que el fenómeno surge con los objetos topicalizados, no es único del español, sino que se extiende al resto de las lenguas románicas y que, una vez que la marca se gramaticaliza completamente en posición dislocada, comienza a extenderse a otros contextos atendiendo ya a las escalas de animacidad y definitud/especificidad. El autor recurre como ejemplos para respaldar su teoría, por un lado, al siciliano antiguo y, por otro, a algunas lenguas cuyo MDO se encuentra aún en un estado incipiente, como es el caso de los dialectos del norte de Italia, el catalán y algunas variedades del francés. En la misma línea, Escandell-Vidal (2009) defiende la importancia de la topicalidad en el MDO del catalán balear, incluso por encima de factores como la animacidad.

Von Heusinger/Kaiser (2005; 2007), por su parte, centran su atención en el proceso de evolución del MDO en español y defienden que la topicalidad constituyó un factor relevante en el desarrollo del fenómeno tan solo durante la expansión del marcado a través de la categoría de los SN definidos. Según estos autores, cuando la marca preposicional ya se había extendido a través de las categorías de los pronombres y los nombres propios, comenzó a extenderse a través de los SN definidos, pero tan solo a través de aquellos topicalizados y, tras esta fase, ya se habría extendido al conjunto de la categoría de los definidos. La situación de transición que estos autores describen, durante la cual la topicalidad se mantuvo como un factor activo en la explicación del MDO, es la que se refleja en el anterior ejemplo de (27). Una vez que la marca preposicional se gramaticalizó con prácticamente la totalidad de los SN definidos humanos, el impacto de la topicalidad quedó desactivado y ello es lo que lleva a los autores a referirse a ella como factor de transición, categoría en la que también incluyen la especificidad por tratarse del factor que está facilitando la expansión del marcado a través del conjunto de los SN indefinidos humanos. 
Por último, en lo que a topicalidad se refiere, cabe destacar el trabajo relativamente reciente de Dalrymple/Nikolaeva (2011). En él parten de la distinción, ya comentada al comienzo de este apartado, entre tópico primario y tópico secundario. Como ya se ha mencionado, la relevancia del tópico secundario se determina a partir de su relación con el tópico primario, lo que hace a este último pragmáticamente más prominente. Dicha prominencia, aunque no existe un alineamiento único entre funciones de la estructura de la información y funciones gramaticales, provoca que el tópico primario se asocie generalmente con la función de sujeto, quedando relegado el tópico secundario a la función de objeto. Las autoras defienden que, en aquellas lenguas que presentan MDO, el marcado se utiliza para diferenciar aquellos objetos que poseen el estatus de tópico secundario de aquellos que no lo poseen (dentro del ámbito de opcionalidad de la marca).

Sin embargo, Iemmolo (2010, 246-247) argumenta en contra de este enfoque señalando que postular la existencia de tópicos secundarios genera varios problemas. En primer lugar, en las estructuras con un constituyente dislocado a la izquierda, pragmáticamente, se interpreta que la información que aportan atañe precisamente al elemento dislocado, en tanto en cuanto la dislocación se lleva a cabo para producir el cambio en la atención de un tópico a otro; resultaría contraintuitivo suponer que el elemento dislocado es el tópico secundario. A ello, además, se le sumaría la dificultad de que las oraciones en el discurso natural son demasiado cortas como para contener cada una de ellas un tópico primario, un tópico secundario y un foco.

Con este panorama de los estudios que han abordado la topicalidad como factor determinante del MDO, quedaría completo el repaso de los factores relacionados únicamente con el SN que desempeña la función de objeto directo. Sin embargo, como ya se mencionaba tanto en la introducción como al comienzo de este capítulo, el MDO es un fenómeno del que no se puede ofrecer una visión completa sin atender también a determinados factores que aluden a la forma en que el objeto está integrado en el evento del que forma parte. El siguiente apartado se ocupa, por tanto, de la agentividad, rasgo ligado a la topicalidad, debido a que esta última queda determinada en parte por el papel temático, como se ha mostrado en (26); y la agentividad es, precisamente, el rasgo fundamental para la asignación de los papeles temáticos.

\subsubsection{Agentividad}

La agentividad es un rasgo semántico de los SN argumentales que se deriva del significado léxico del verbo al que acompañan; por lo tanto, a diferencia de los factores estudiados hasta el momento, esta característica no es inherente al SN 
ni se desprende de sus propiedades discursivo-referenciales, sino que depende de forma directa de la semántica verbal y hace referencia a la forma en que el SN participa en el evento designado.

La noción de agentividad surge asociada al estudio de las relaciones temáticas (más tarde conocidas como papeles temáticos), que no designan otra cosa que la interpretación semántica de los distintos argumentos de un predicado. Aunque el término relaciones temáticas fue introducido por Gruber (1965) y se hizo ampliamente conocido a través del trabajo de Jackendoff (1972), los papeles temáticos como categorías semánticas son producto en gran medida de los casos profundos definidos en la Gramática de Casos propugnada por Fillmore (1966; 1968).

La relación entre funciones sintácticas y semánticas ha sido, sin duda, uno de los temas más controvertidos en lingüística desde el mismo momento de su planteamiento, y, por ello, en este trabajo no se abordarán las diferentes teorías que se han propuesto sobre la interacción entre sintaxis y semántica, ni se pretende presentar la polémica que rodea a la cantidad de papeles temáticos que existen o a la definición de cada uno de ellos, pues estas cuestiones excederían en gran medida los propósitos del trabajo.

No obstante, a pesar de la diversidad de teorías, la noción de agentividad se ha mantenido como una constante en cuanto que propiedad definitoria del participante que lleva a cabo la acción designada por el verbo y que suele corresponderse con la función sintáctica del sujeto. De aquí en adelante, los estudios que se mencionan están basados fundamentalmente en el trabajo de Dowty (1991), según el cual tan solo es necesario establecer la existencia de dos Proto-roles o Proto-papeles temáticos no discretos (Proto-agente y Proto-paciente), en vez de una serie de papeles temáticos más extensa, pero de difícil definición objetiva.

Según Dowty (1991, 572), cada uno de los dos Proto-papeles está asociado a una serie de características semánticas, basadas en trabajos anteriores como el de Lakoff (1977), que son las que los definen y las que aparecen recogidas en (28) y (29).

(28) Características constitutivas del papel de PROTO-AGENTE

a. Implicación volitiva en el evento.

b. Percepción.

c. Causación de un evento o cambio de estado en otro participante.

d. Movimiento en relación con la posición de otro participante.

e. Existencia independiente del evento designado por el verbo.

(29) Características constitutivas del papel de PROTO-PACIENTE

a. Experimentación de un cambio de estado.

b. Tema incremental. 
c. Afectación causal por otro participante.

d. Posición estacionaria con respecto al movimiento de otro participante.

e. Existencia dependiente del evento (si se trata de un predicado de existencia).

Estas propiedades son independientes unas de otras (en casi todos los casos) y no tienen por qué aparecer siempre de manera conjunta. Para interpretar un argumento como Proto-agente no es necesario que el participante asociado posea todas las características indicadas en (28), sino simplemente una cierta cantidad de ellas en comparación con las del resto de participantes. A partir de la descripción de los Proto-papeles, Dowty propone el que denomina principio de selección argumental (1991, 576), según el cual «en estructuras predicativas en las que hay un sujeto y un objeto gramatical, el argumento con el que el predicado asocia mayor número de propiedades de Proto-agente será lexicalizado como el sujeto de dicho predicado». De este principio se desprende, además, una idea que resulta de interés para el presente trabajo y es que, según Dowty, si dos argumentos poseen aproximadamente el mismo número de características proto-agentivas, cualquiera de los dos podría ser lexicalizado como sujeto; y este tipo de situaciones excepcionales son las que justifican la función desambiguadora del MDO con los inanimados (véase 6.3.2).

Primus (1999) desarrolla el modelo de Dowty y lleva a cabo algunos cambios en él. En primer lugar, defiende que el verbo aporta dos tipos diferentes de información temática a través de la cual se definen los Proto-papeles: por un lado, establece relaciones de implicación y, por otro, relaciones de dependencia. Respecto al primer tipo de información, el verbo implica el número de argumentos y el contenido de cada uno; y, en lo que al contenido se refiere, cada argumento queda definido por las cuatro primeras características definidas por Dowty, a excepción de que la volición es sustituida por la noción más amplia de control y que se añade la posesión como una nueva característica del Proto-agente. Por otro lado, en lo que se refiere al segundo tipo de información temática, es decir, la dependencia, Primus argumenta que la última de las características propuestas por Dowty para cada uno de los Proto-papeles, la dependencia existencial y referencial, realmente captura tan solo uno de los aspectos de una propiedad más general que opera sobre los Proto-agentes y los Proto-pacientes y, por ello, esta relación de dependencia temática no debe ser contemplada a la par del resto de características. Su propuesta defiende que las relaciones de dependencia temática entre participantes se describen de una manera más apropiada atendiendo a su posición estructural relativa en la representación temática de los verbos o las oraciones.

Partiendo de esta base, Primus (1999; 2006; 2012) y García García (2007; 2014) sostienen que la explicación que tradicionalmente se ha dado al MDO en algunas 
lenguas, en términos de animacidad, presenta problemas para abordar algunos ejemplos en los que aparece la marca preposicional; ya que realmente no se trata de una cuestión de animacidad, sino de agentividad. García García (2007; 2014), basándose en el denominado principio de distinción semántica (Weissenrieder 1985; de Swart 2003), estudia los casos de MDO en español con inanimados y defiende que han de marcarse preposicionalmente aquellos objetos a los que el sujeto no supere en términos de agentividad. Los ejemplos de (30) representan un conjunto de casos en los que determinados verbos exigen la marca preposicional en español a pesar de que el objeto sea inanimado. Este tipo de verbos tradicionalmente se ha considerado una clase semántica «especial» (Torrego 1999; Fernández Ramírez 1986 [1951]), que por sus características exige MDO; Roegiest (1990), de hecho, los define como verbos de transitividad atípica. No obstante, señala García García, los objetos directos de estos casos se caracterizan por presentar un grado de implicación en el evento similar al de sus respectivos sujetos, es decir, que los dos argumentos de cada oración presentan un número similar de proto-propiedades; por lo tanto, basándose en la adaptación del principio de distinción semántica que propone, García García sostiene que el MDO en estos casos lo explica la necesidad de distinguir temáticamente dos argumentos tan similares en lo que a proto-propiedades respecta.

(30) MDO con SN inanimados en español (Torrego 1999, 1788)

a. Los dias siguen a las noches.

b. El uno precede al dos.

c. Esta cuesta supera a aquella.

d. En esta receta, la leche puede sustituir al huevo.

Todos estos trabajos amplían el estudio del MDO más allá de los límites del SN que funciona como objeto. De esta manera, queda demostrado el impacto que produce sobre el fenómeno la relación entre las propiedades semánticas que el verbo asigna a cada uno de sus dos argumentos principales, es decir, sujeto y objeto. ${ }^{4}$ No obstante, el grado de agentividad del objeto con relación al del sujeto no es el único factor derivado de la semántica verbal cuya influencia se ha postulado sobre el MDO. La telicidad y la afectación son dos propiedades, asimismo,

\footnotetext{
4 Torrego (1999, 1785-1786) pone de relieve asimismo el factor de la agentividad, pero fijando su atención tan solo en el grado de agentividad del sujeto. Según la autora, la presencia del MDO lleva siempre aparejada la presencia de un sujeto agente. Esta idea encaja con la argumentación esgrimida en el capítulo 6, mediante la cual es necesario un Agente que desencadene la transmisión de fuerza al resto de argumentos para que estos se perciban como afectados y puedan recibir el marcado (véase apartado 6.3).
} 
relacionadas con la semántica del núcleo verbal, cuya influencia en el marcado preposicional ha sido apuntada en diversas ocasiones, pero que, sin embargo, no han recibido suficiente atención, al menos en español; por esta razón, estos factores constituyen el núcleo de esta investigación y serán abordados con mayor profundidad en los siguientes apartados.

\subsubsection{Telicidad}

\subsubsection{El concepto de telicidad}

La reflexión sobre el concepto de telicidad se remonta a los comienzos de la filosofía clásica. Ya en el siglo IV a.C., Aristóteles distinguía distintos tipos de acciones atendiendo a la necesidad de estas de alcanzar un punto final o culmi-

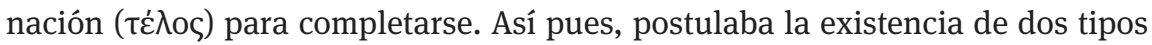
de acciones: (i) las que constituían un acto en sí mismas ('́vépycı $\alpha$ ) y (ii) aquellas que tendían hacia un punto final sin el cual no se completaba el propio acto (кívnбıৎ). ${ }^{5}$ Sin embargo, no sería hasta mediados del siglo xx cuando la lingüística se ocuparía con mayor profundidad de este tema.

El término telicidad fue acuñado por Garey $(1957,106)$ a partir del concepto

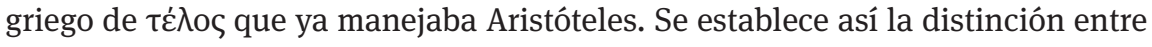
dos clases de verbos: télicos y atélicos. Los primeros expresan acciones orientadas hacia un punto final, como hundirse o llegar; por el contrario, los verbos atélicos denotan acciones que no necesitan alcanzar meta alguna para para considerarse realizadas, sino que se considera que han tenido lugar tan pronto como comienzan, como, por ejemplo, nadar o jugar.

Con el fin de determinar la telicidad de un verbo, Garey propone la prueba de implicación que se presenta a continuación en (31):

(31) Prueba de telicidad (Garey 1957, 109)

a. Una construcción atélica en un tiempo imperfectivo implica la construcción atélica perfectiva correspondiente: Él está nadando $\Rightarrow$ Él ha nadado

b. Una construcción télica en un tiempo imperfectivo no implica la construcción télica perfectiva correspondiente:

Él está construyendo una casa $\nRightarrow$ Él ha construido una casa

5 Aris. Met. IX, 4. 
No obstante, aunque Garey es quien acuña el término telicidad, una de las aportaciones más relevantes al estudio del aspecto léxico ha sido, sin duda, el trabajo de Vendler (1957). En dicho trabajo el autor establece las cuatro clases aspectuales de verbos que, salvo algunas modificaciones, han constituido la base para la mayoría de los desarrollos teóricos posteriores acerca del tema.

Según Vendler, existen cuatro clases aspectuales de verbos: los estados (states), como saber o conocer; las actividades (activities), que incluyen acciones como correr o empujar un carro; las realizaciones (accomplishments), integradas por predicados como correr un kilómetro o dibujar un círculo; y los logros (achievements), con ejemplos como alcanzar la cima o ganar la carrera. Estas cuatro categorías se definen atendiendo a la presencia o ausencia de tres rasgos determinados: dinamicidad, duración y delimitación. ${ }^{6}$ En la Tabla 2.1 se recoge la distribución de dichos rasgos a través de las diferentes clases aspectuales.

Tabla 2.1: Clasificación aspectual de los verbos (Bosque/Gutiérrez-Rexach 2009, 301).

\begin{tabular}{lccc}
\hline & dinamicidad & duración & delimitación \\
\hline estado & - & + & - \\
\hline actividad & + & + & - \\
\hline realización & + & + & + \\
\hline logro & + & - & + \\
\hline
\end{tabular}

La delimitación sería equivalente a la telicidad en este caso, es decir, los verbos atélicos o no delimitados se corresponderían con los estados y las actividades; mientras que los télicos o delimitados serían las realizaciones y los logros. La prueba que aplica Vendler para comprobar si un verbo o, mejor dicho, un predicado es télico consiste en la adición al enunciado de un adjunto encabezado por la preposición en, seguida de una expresión temporal como muestran los ejemplos de (32); es decir, un adjunto que manifieste de forma explícita el límite de tiempo en el que finaliza un evento o tras el cual deja de tener lugar. Los estados y las actividades, representados en (32a) y (32b), no admiten dicha manifestación de un límite, pues carecen de él; sin embargo, las realizaciones y los logros

6 La presentación de las clases definidas de esta manera se debe simplemente a la intención de facilitar al lector la comprensión de la idea fundamental; sin embargo, Vendler (1957) no plantea la distinción en términos de presencia/ausencia de rasgos, sino simplemente atendiendo a los resultados que se obtienen de someter a los verbos a las distintas pruebas que se mencionan en este apartado. 
admiten sin ningún problema el sintagma preposicional (SP) delimitador, como se muestra en (32c) y (32d).

(32) Prueba de telicidad (Vendler 1957, 145-146)

a. \#Pedro supo/conoció la respuesta (en dos minutos).

b. \#María corrió/empujó un carro (en dos minutos).

c. Luis corrió cincuenta metros/dibujó un circulo (en diez segundos).

d. Ana alcanzó la cima/ganó la carrera (en treinta minutos).

Esta prueba es la que ha continuado utilizándose hasta la actualidad para examinar la telicidad de un predicado y, por ello, es también la que ha sido utilizada en la presente investigación para llevar a cabo tanto los cuestionarios como el análisis de corpus, presentados en los capítulos 4 y 5.

Respecto a la clasificación cuatripartita de Vendler, cabe señalar que no siempre se ha mantenido intacta, sino que algunos autores han intentado perfeccionarla añadiendo o reduciendo el número de categorías; por ejemplo, Smith $(1991,29)$ incluye los semelfactivos (semelfactives), cuyos rasgos serían [+dinámico], [-durativo] y [-delimitado]. La autora los diferencia de los logros únicamente por la telicidad o delimitación, argumentando que, mientras que los logros implican algún tipo de cambio o resultado, los semelfactivos, no. Sin embargo, en esta tesis se ha decidido no incluirlos puesto que partimos de que la cualidad de instantaneidad que conlleva la ausencia de duración implica, asimismo, la delimitación del propio evento. Ejemplos prototípicos de verbos semelfactivos, según Smith, serían llamar a la puerta o batir las alas.

Llegados a este punto, es importante señalar que, aunque Vendler hace referencia a la clasificación de los distintos tipos de verbos, lo que genera el límite de las acciones descritas en algunos casos no es el propio verbo en sí, sino el objeto directo, como puede deducirse de la comparación entre (32b) y (32c), donde el verbo correr puede dar lugar tanto a un predicado de actividad como a uno de realización, dependiendo de si presenta o no objeto directo. Esta es una idea que ya señalaba el propio Garey. Así pues, sin desdeñar la clasificación «verbal» de Vendler, los trabajos posteriores acerca del aspecto léxico y la telicidad han ido dirigidos fundamentalmente a desentrañar cuál es el papel que juega el objeto directo en la construcción de la telicidad y a investigar si, además del objeto, hay otros elementos que contribuyan a la determinación del valor aspectual.

Verkuyl (1972) es uno de los primeros autores en señalar la composicionalidad de la telicidad. Este autor sostiene que la distinción télico/atélico ${ }^{7}$ se corres-

7 Verkuyl hace referencia realmente a la distinción durativo/no durativo. 
ponde con la existencia de las dos configuraciones sintáctico-semánticas que aparecen recogidas en (33).

(33) Posibles configuraciones aspectuales (Verkuyl 1972, 58-59)

a. Aspecto atélico: SV[ V[verbo] + SN[cantidad inespecífica de x]] Ej. Juan bebió cerveza.

b. Aspecto télico: SV[ V[verbo] + SN[cantidad específica de $\mathrm{x}]]$ Ej. Juan bebió un vaso de cerveza.

Estas configuraciones se definen esencialmente atendiendo a dos factores: (i) la semántica del verbo y (ii) la semántica del argumento interno. Señala Verkuyl que además de la distinción léxica entre verbos télicos y verbos atélicos es necesario tener en cuenta la naturaleza del argumento interno y, tan solo de la suma de ambos, se podrá obtener un tipo u otro de estructura. Se distinguen, a este respecto, dos tipos de argumento interno: (i) los que expresan una cantidad específica de la materia o el elemento al que hace referencia el SN y (ii) aquellos cuya cantidad es inespecífica. Asimismo, el autor defiende que, no solo el argumento interno, sino también algunos adjuntos, pueden especificar los límites del evento y, por tanto, producir estructuras télicas, como puede apreciarse en (34b), donde correr, que expresa una actividad inherentemente atélica, da lugar a un predicado télico al combinarse con un argumento que denota una cantidad específica (de distancia en este caso) o con un adjunto que hace referencia a la meta del desplazamiento implicado por el verbo.

(34) Posibles modificaciones del valor aspectual del verbo

a. Jorge corrió. (atélico)

b. Jorge corrió dos kilómetros/hasta el colegio. (télico)

Verkuyl señala que la «cantidad específica de x» o la «cantidad inespecífica de $\mathrm{x}$ » se asocian directa o indirectamente al eje temporal, es decir, las cantidades implicadas son expresables en términos de conjuntos de entidades temporales linealmente ordenadas $(1972,96)$. Esta idea es fundamental para el desarrollo de la teoría de las estructuras de partes y, en este sentido, el trabajo de Krifka (1988; 1989; 1998) quizá sea uno de los más destacados.

Krifka $(1998,197)$ sostiene que «las propiedades aspectuales de un predicado proceden de dos fuentes, la naturaleza del núcleo verbal y la naturaleza de un argumento nominal»; y, retomando la teoría de Verkuyl, defiende que las estructuras de partes no son útiles únicamente para describir eventos, sino también para explicar la semántica de los SN. La idea fundamental es que existen dos tipos de predicados atendiendo a la estructura de sus partes: (i) los predicados 
acumulativos y (ii) los predicados cuantificados. El hecho que define a los primeros es que cada una de sus partes posee las mismas propiedades designativas que el conjunto de ellas; en cambio, esto no ocurre con los segundos; cada una de las partes de un predicado cuantificado, no posee las mismas propiedades que el conjunto de todas ellas. Como se aprecia en los ejemplos de (35a), las distintas partes de cada uno de ellos conservan las propiedades referenciales de la totalidad del predicado, es decir, un poco de agua continúa siendo agua o uno de los intervalos que implica el evento de correr continúa siendo correr. Por el contrario, esta relación entre las partes y el todo no se mantiene en el caso de los ejemplos recogidos en (35b). No tiene sentido afirmar que un litro de agua sean tres litros de agua o que un intervalo del evento al que hace referencia correr tres kilómetros pueda ser considerado correr tres kilómetros. Se establece, por lo tanto, una cierta correlación entre predicados cuantificados y telicidad, y, por otro lado, entre predicados acumulativos y atelicidad.

(35) Tipos de predicados (Krifka 1998, 199)

a. Predicados acumulativos

- SN: agua, manzanas

- SV: correr, comer

b. Predicados cuantificados

- SN: tres litros de agua, tres manzanas

- SV: correr un kilómetro, comer tres manzanas

Partiendo de esta base, Krifka pretende formalizar la idea propuesta por Verkuyl de que el objeto denotado por el argumento interno se relaciona de alguna manera con la línea temporal o, lo que es lo mismo, con el transcurso del evento. Así pues, esta propuesta es la que encontramos recogida en (36).

(36) Proyección a eventos (Krifka 1989, 92-93)

Suponiendo que $R$ es la relación denotada por un verbo transitivo y que $R$ se da entre un individuo $x$ y un evento $e$. El evento $e$ culmina con respecto a $x$ solo en el caso de que para cada parte $x$ ' de $x$ haya una parte $e$ ' de $e$ tal que $R$ se dé entre $x^{\prime}$ y $e^{\prime}$.

En definitiva, la idea es que se establece una relación, determinada por la semántica del verbo, entre cada una de las partes en las que se puede dividir la entidad denotada por el argumento interno y cada una de las partes en las que se puede dividir el evento. Consecuentemente, aquellos SN que conformen predicados cuantificados conducirán a la creación de eventos télicos, mientras que aquellos argumentos que se constituyan como predicados acumulativos implicarán interpretaciones atélicas del evento. 
La idea del argumento interno como constituyente con capacidad para medir el evento ha sido extremadamente productiva en la bibliografía acerca del aspecto léxico (Dowty 1979; Krifka 1988; 1989; Dowty 1991; Tenny 1994; Jackendoff 1996; Krifka 1998; entre otros); y, por mencionar alguno de los conceptos a los que ha dado pie, podría citarse el de tema incremental, desarrollado fundamentalmente por Krifka (1988; 1989) y Dowty (1991). Esta noción se aplica precisamente a aquellos argumentos internos con capacidad de medir el evento o, lo que es lo mismo, a aquellos SN constituidos por predicados cuantificados (en palabras de Krifka) cuya estructura delimitada de partes delimita la estructura del evento completo.

Continuando con la idea del argumento interno como elemento relevante para la computación de la telicidad, un trabajo asimismo fundamental es el de Tenny (1987; 1994). Dicho trabajo no explora tan solo la contribución del argumento interno a la construcción del aspecto léxico o, más concretamente, de la telicidad, sino que presenta de forma sistemática cuáles son los demás constituyentes que pueden contribuir a este fin, y de qué forma o en qué medida puede hacerlo cada uno de ellos. Esta idea ya había sido abordada en otros trabajos que hemos mencionado, pero quizá no de forma tan extensa.

Partiendo de la distinción entre argumento externo, argumento interno directo y argumento interno indirecto, ${ }^{8}$ Tenny establece una serie de restricciones para cada uno de ellos en lo que se refiere a su contribución al concepto de telicidad. En primer lugar, destaca que el único argumento capaz de medir el evento es el argumento interno directo y señala que puede hacerlo de tres maneras: (i) cuando acompaña a un verbo de tema incremental, (ii) acompañando a un verbo de cambio de estado o (iii) con un verbo de ruta, si se trata de un objeto de trayectoria (path object). Estas tres situaciones aparecen ejemplificadas en (37).

(37) Formas de medir el evento (Tenny 1994, 15)

a. Verbos de tema incremental: construir una casa, comer una manzana

b. Verbos de cambio de estado: madurar la fruta

c. Verbos de ruta con objeto de vía: hacer (la ruta de) el sendero de los Apalaches

8 Es importante en este punto no confundir la noción de argumento interno indirecto con la función clásica de complemento indirecto. Con dicha noción Tenny hace referencia simplemente a aquellos constituyentes con que el verbo completa su significado y que se encuentran en una posición sintáctica interior al SV, pero no complementan directamente al núcleo. 
En cuanto a los argumentos internos indirectos, ${ }^{9}$ Tenny sostiene que pueden otorgar un terminus o punto de culminación a los eventos; sin embargo, esto no significa que los puedan medir, a diferencia de lo que ocurre con los argumentos internos directos. Aun así, el proporcionar un punto de culminación conduce a los argumentos internos indirectos a participar de la estructura aspectual del evento. Esta idea aparece reflejada en los ejemplos de (38), donde hasta el final del sendero y hasta el final de la escalera introducen el punto en que el evento se da por completado.

(38) El argumento interno indirecto en la construcción de la telicidad

a. caminar hasta el final del sendero

b. subir hasta el final de la escalera

Es interesante señalar que la apreciación de que los distintos argumentos del verbo contribuyen de manera diferente en la construcción de la telicidad la han contemplado, asimismo, otros autores. Krifka $(1998,9)$, por ejemplo, señala que, aunque todos los predicados cuantificados son télicos, no todos los predicados télicos son cuantificados, es decir, la cuantificación es una noción más restringida que la telicidad o, en palabras de Tenny, la capacidad de medir el evento es una noción más restringida que la capacidad de delimitarlo. Los ejemplos de (39) muestran esta diferencia. En (39a), el argumento interno directo mide el evento y, por lo tanto, lo delimita; en palabras de Krifka, una maratón constituye un predicado cuantificado y, por lo tanto, cada uno de los $42.195 \mathrm{~m}$ con los que cuenta se corresponderán con un intervalo temporal del evento; de manera que, completada la totalidad de los metros, se verá asimismo completado el evento. Por otro lado, en el caso de (39b), hasta las cinco de la tarde no se puede dividir en partes que se correspondan con intervalos del evento; sin embargo, dicho adjunto proporciona un límite temporal explícito al evento y, por lo tanto, el resultado es asimismo un predicado télico.

(39) Medición/delimitación del evento

a. Luis corrió una maratón.

b. Luis corrió hasta las cinco de la tarde.

Por último, en lo que concierne a los argumentos externos, Tenny mantiene que no pueden participar de manera alguna en la construcción de la estructura aspectual. No obstante, esta afirmación ha sido discutida por algunos autores, que han defendido la influencia, al menos indirecta, no solo del sujeto, sino también del

9 Véase nota 8 a pie de página. 
aspecto gramatical, en lo que se refiere a la computación de la telicidad. En este sentido pueden destacarse, entre otros muchos, los trabajos de Travis (2010), Filip (2004), De Miguel (1999) y Hay/Kennedy/Levin (1999). En ellos se defiende la influencia (indirecta) del argumento externo y del aspecto gramatical, al encontrarse ambos en una posición superior al SV en la estructura sintáctica. No obstante, dicha influencia se reduce a contextos relativamente escasos y ni siquiera se produce de forma directa en lo que al establecimiento de un límite o punto final se refiere. Así pues, de aquí en adelante, en este trabajo la telicidad será considerada una propiedad que caracteriza al SV y que se genera mediante la interacción de la clase aspectual del verbo, las propiedades del objeto directo y la posible intervención de adjuntos con función delimitadora.

La función de este subapartado ha sido la de demostrar hasta qué punto la noción de telicidad se ha ligado al argumento interno en la bibliografía. Como se ha mostrado, las características que definen al objeto directo están íntimamente relacionadas con el valor aspectual que adquiere el SV. De esta manera, los predicados cuantificados, en términos de Krifka, dan lugar a interpretaciones télicas, mientras que los predicados acumulativos, implican lecturas atélicas; teniendo en cuenta que, como se ha mencionado en los apartados anteriores, un objeto directo más individualizado tiene más probabilidad de aparecer marcado, los predicados cuantificados, asimismo, tendrán más posibilidades de presentar MDO que los predicados acumulativos. En conclusión, parece existir una relación entre las propiedades del objeto directo que conducen al uso del MDO y aquellas que implican una lectura télica del predicado.

\subsubsection{Telicidad y MDO}

La relación que acaba de ser expuesta entre MDO y telicidad ha conducido a que diversos autores hayan establecido una correlación directa entre ambos elementos. Esta correlación ha sido defendida con especial énfasis en el grupo de las lenguas fino-bálticas. En lenguas como el lituano, el objeto directo de determinados verbos puede aparecer tanto en acusativo como en partitivo. Esta diferencia en el marcado de caso da lugar a diferentes lecturas, como se puede apreciar en (40), donde, en el primer caso, el verbo pagére 'beberse', que es un verbo inherentemente télico, selecciona un argumento en acusativo y esto da lugar a dos lecturas: una que implica la interpretación definida del objeto y otra que implica una interpretación indefinida; no obstante, en ambos casos el evento descrito es de carácter télico. Sin embargo, en (40b), el argumento interno aparece en caso genitivo y ello imposibilita la lectura definida del objeto, pero, además, provoca un cambio aspectual en el evento, que pasa a convertirse en un predicado de actividad, es decir, atélico. 
(40) MDO en lituano (Seržant/Witzlack-Makarevich 2018, 15)
a. Jis
iš-gère
vanden- $i$
él.NOM TELIC-beber.PST.3SG agua-ACC.SG
'Él se bebió (el/un poco de) agua.'
b. Jis iš-gèrè vanden-s
él.NOM TELIC-beber.PST.3SG agua-GEN.SG 'Él bebió agua.'

Esta relación entre la marca de caso acusativo y la lectura télica del evento no es única del lituano, sino que se extiende de forma muy similar a otras lenguas de la misma familia, como en el caso del finés, lengua que se ha utilizado tradicionalmente para ejemplificar este tipo de contrastes. En finés, al igual que en lituano, mientras que los verbos inherentemente atélicos siempre seleccionan partitivo, los verbos inherentemente télicos muestran variación respecto a la forma que puede presentar su objeto directo. La posibilidad de elegir entre marcar el objeto con acusativo o hacerlo con partitivo da lugar a un cambio aspectual en la lectura del enunciado. Siguiendo a Kiparsky (1998, 266), el enunciado de (41a) denota una actividad en el sentido de 'disparar en una determinada dirección', sin que ello implique ningún tipo de resultado o cambio alguno en el objeto, es decir, se corresponde con una interpretación atélica del evento. En lo que a (41b) se refiere, por el contrario, se obtiene una lectura télica o resultativa, que implica un cambio en el objeto, es decir, el enunciado denota una situación en la que el disparo alcanza al oso y (muy posiblemente) lo mata.

(41) MDO en finés (Kiparsky 1998, 266)
a. Ammu-i-n karhu-a.
disparar-PST-1SG oso-PART
'Disparé al/a un oso.'
b. Ammu-i-n karhu-n.
disparar-PST-1SG oso-ACC
'Disparé al/a un oso (y lo maté).'

Como se ha observado, el uso de la marca de acusativo en estas lenguas se muestra estrechamente ligado al valor télico de los eventos y precisamente este hecho es el que algunos autores han pretendido relacionar con el uso del MDO en español. La idea de que la telicidad representa en español un factor fundamental para explicar el marcado preposicional del objeto directo está basada principalmente en los trabajos de Torrego (1998; 1999; 2002). Esta autora defiende que, tras la animacidad y la definitud del objeto, la telicidad es en español el factor que determina el dominio de obligatoriedad del marcado, pues «los verbos llamados télicos imponen 
la preposición $a$ del complemento directo animado» $(1999,1787)$. Este hecho quedaría ejemplificado mediante el contraste de (42), en el que aparece el verbo insultar (inherentemente télico) acompañado de un objeto directo introducido por la preposición en (42a) y la misma estructura, pero sin MDO, en (42b), hecho que provoca la agramaticalidad del enunciado.

(42) MDO con verbos télicos en español (Torrego 1998, 1787)

a. Marta insultó a un compañero.

b. *Marta insultó un compañero.

En lo que respecta a los verbos inherentemente atélicos, Torrego afirma que no exigen forzosamente el uso del MDO con los objetos indefinidos humanos, como ocurre en el caso de los verbos télicos; no obstante, el comportamiento aspectual de estos verbos se ve afectado en el caso de aparición del marcado. Según la autora, el uso de MDO con verbos atélicos desencadena una lectura télica del evento, de forma paralela a lo que ocurre, por ejemplo, en finés ante el uso del caso acusativo (frente al partitivo) en los casos en los que la variación es posible. Este hecho es el que explicaría que tanto (43a) como (43b) puedan ser posibles, aunque den lugar a diferentes interpretaciones. El verbo besar, inherentemente atélico, no exige el MDO y ello es lo que da pie a que tanto (43a) como (43b) sean gramaticales; sin embargo, el uso de la marca preposicional en (43b) implicaría una lectura télica del evento y, por ello, sería posible añadir un adjunto delimitador, cosa que no ocurre en (43a).

(43) MDO con verbos atélicos en español

a. Besaron un niño ( ${ }^{\star}$ en un segundo).

b. Besaron a un niño (en un segundo).

El uso de la marca tiene aparejado un efecto individualizador del objeto, que lo destaca como participante del evento y lo hace coincidir, según Torrego, con el punto final del evento (2002, 62). Por todo ello, la autora establece la siguiente generalización a propósito del español: «el complemento preposicional de un verbo hace que el evento se entienda como télico incluso si el verbo aisladamente designa un evento atélico» (Torrego 1999, 1790).

La propuesta de Torrego de relacionar el MDO con la interpretación télica de los eventos no ha sido analizada hasta la actualidad en profundidad y las críticas o el cuestionamiento de la idea simplemente se ha llevado a cabo por medio de breves comentarios en algunos trabajos. Delbecque (2002, 95-97) sostiene que la telicidad de la interpretación en muchos casos depende del contexto y no de la aparición de la marca preposicional, como sostiene Torrego. Señala que 
todos los ejemplos en los que Torrego basa sus afirmaciones se encuentran en pretérito indefinido y que la perfectividad podría coaccionar en muchos casos la interpretación de los predicados. En el transcurso del discurso habitual, apunta Delbecque, el MDO aparece también con verbos en imperfecto y la interpretación télica no parece estar tan clara a pesar del uso del marcador preposicional, pues se mantiene la ambigüedad entre incoatividad y terminación, es decir, entre si el SP delimitador se refiere al tiempo que transcurre antes de que comience la acción (44b) o al intervalo que ocupa la realización del acto de insultar/conocer en sí (44c).

(44) Perfectividad y coacción aspectual

a. En su juventud el disidente insultaba/conocía a un dignatario en menos de un minuto, ahora tarda algo más.

b. En su juventud el disidente tardaba en comenzar a insultar/conocer a un dignatario menos de un minuto, ahora tarda algo más.

c. En su juventud el disidente llevaba a cabo el acto de insultar/conocer a un dignatario en el intervalo de un minuto, ahora tarda algo más.

Asimismo, Fábregas $(2013,25)$ sostiene que no todos los hablantes comparten la percepción de Torrego acerca de las interpretaciones de sus ejemplos y que, en todo caso, aunque el MDO es compatible con un lectura télica del evento cuando acompaña a verbos inherentemente atélicos, no tiene por qué implicarla.

De una forma $u$ otra, la telicidad no es el único factor relacionado con la semántica verbal que Torrego destaca respecto al uso del MDO en español. Además de la agentividad del sujeto y de la interpretación télica del predicado, la autora defiende la influencia del grado en que el objeto queda afectado por la acción que describe el verbo; por ello, el siguiente apartado está dirigido a presentar una visión amplia del concepto de afectación, así como a indagar en la influencia que dicho factor ejerce sobre el marcado preposicional, fundamentalmente en español.

\subsubsection{Afectación}

\subsubsection{El concepto de afectación}

La noción de afectación comienza a extenderse a finales de los años 60 y lo hace, generalmente, asociada a las distintas teorías acerca de la asignación de papeles temáticos que, de la misma manera, comienzan su andadura en esta misma época. Uno de los primeros trabajos en hacer referencia al carácter afectado de los objetos de determinados verbos es el de Fillmore (1968). En dicho trabajo, el 
autor señala el estatus afectado del objeto, entre otra serie de rasgos, para definir los casos profundos ${ }^{10}$ (o papeles temáticos) Dativo y Objetivo. ${ }^{11}$ De esta forma, tal y como recoge (45), el caso Dativo se caracterizaría fundamentalmente por ser animado y quedar afectado por la acción del verbo; mientras que el caso Objetivo quedaría definido tan solo por el segundo de los rasgos.

(45) Definición de los casos dativo y objetivo (Fillmore 1968, 24-25)

a. Dativo: caso del ser animado afectado por la acción o el estado referido por el verbo.

b. Objetivo: [. . .] caso de cualquier cosa representable por un nombre cuyo papel en la acción o estado referido por el verbo sea identificado por la interpretación semántica del propio verbo; posiblemente el concepto debería estar limitado a cosas que estén afectadas por la acción o el estado referido por el verbo. ${ }^{12}$

A lo largo de las últimas décadas del siglo xx y el comienzo del siglo xxi, los autores que han recurrido a la noción de afectación han sido numerosos, sin embargo, el sentido que se le ha dado al término no ha sido equivalente en todos los casos; de hecho, han sido escasos los estudios que han intentado definirlo de una forma precisa e independientemente motivada, tal como señala Beavers (2011, 336).

La afectación ha sido explicada generalmente con respecto a una serie de estructuras y fenómenos gramaticales como las construcciones nominales pasivas (Anderson 1979; Fiengo 1980), las construcciones medias (Roberts 1987; Hale/Keyser 1992) y pasivas (Jaeggli 1986), las estructuras causativas (Alsina 1992; Ackerman/Moore 1999), la determinación del aspecto léxico (Tenny 1987; Jackendoff 1990; Tenny 1994; Krifka 1998; Beavers 2010; 2011) y la transitividad (Hopper/Thompson 1980; Tsunoda 1985; Blume 1998; Testelec 1998; Næss 2007).

A pesar de la diversidad de aspectos para los que se ha recurrido a la noción de afectación, Lambert $(2010,26)$ considera que los estudios que lo han utilizado se pueden clasificar en dos grandes bloques atendiendo a la forma de entender el concepto que ha manifestado cada uno: por un lado, aquellos que le han dado

10 La noción de caso utilizada por Fillmore (1966) en esta ocasión hace referencia a lo que él denomina casos profundos, por contraposición a los casos superficiales o casos gramaticales que son los que se reflejan de manera morfológica en los argumentos.

11 El nombre de los distintos casos aparece escrito con mayúscula para mantener la grafía que utiliza el propio Fillmore y distinguirlos así más fácilmente de los casos gramaticales.

12 He añadido la negrita en esta cita para destacar los objetos de interés; el texto original no mostraba ningún tipo de marca. 
un sentido espacio-temporal y, por otro, aquellos que lo han entendido como el resultado de una transmisión de fuerza.

El primer enfoque, el espacio-temporal, está basado en la noción de cambio, ya sea en sentido estricto o en sentido metafórico y ya se trate de cambio físico o de posición. Así pues, desde esta perspectiva se consideran afectados aquellos objetos que experimentan algún tipo de cambio una vez finalizado el evento del que forman parte. Una de las primeras autoras en defender esta idea es Tenny (1987; 1994). Esta autora, como ya se ha mencionado en el apartado anterior, sostiene que el argumento interno es capaz de medir el evento, en los casos en que este proyecta su estructura de partes sobre el eje temporal y, por lo tanto, las partes en que queda dividido el objeto son las partes en las que se puede dividir el evento. Ateniéndose a este planteamiento, Tenny equipara las nociones de objeto con capacidad para medir un evento y objeto afectado, teniendo en cuenta que el evento lo que describe es precisamente el proceso de cambio que experimenta el objeto y que finaliza cuando han quedado afectadas todas sus partes. Las principales críticas que ha recibido este planteamiento se deben fundamentalmente a su extremada rigidez que, aunque explica casos como los de (46a) y (46b), deja fuera a su vez ejemplos como los de (46c) y (46d), en cuyos objetos se presupone asimismo un cambio, a pesar de no medir el evento.

(46) Objetos directos afectados

a. Luis se comió la manzana.

b. El inquisidor quemó a la bruja.

c. María calentó la leche.

d. La policía apaleó a los manifestantes.

No obstante, otro autor que ha trabajado en esta misma línea, pero cuya noción de afectación es más abarcadora, ha sido Beavers (2010; 2011). Este autor aboga por la independencia de afectación y telicidad, aunque reconoce su relación. En sus trabajos argumenta que la primera es una noción gradual que se puede estructurar atendiendo a la escala presentada en (47), mientras que la segunda constituye el rasgo que define tan solo el grado más alto de afectación que puede presentar un objeto.

(47) Escala de afectación: para todo $x, \emptyset, e$, (Beavers 2011, 359)

$\exists s\left[\operatorname{result}^{\star}\left(x, s, \mathrm{~g}_{\varnothing}, e\right)\right] \rightarrow \exists s \exists g\left[\operatorname{result}^{\star}(x, s, g, e)\right] \rightarrow \exists s \exists \theta[(x, s, e)] \rightarrow \exists \theta^{\star}\left[\theta^{`}(x, e)\right]$

cuantificados

no-cuantificados

potenciales no específicos 
La escala de afectación de Beavers divide los predicados atendiendo a cuatro grados. El grado más alto de la escala estaría constituido por los predicados cuantificados, que se definen por implicar un cambio de estado cuantificado y, por lo tanto, por ser télicos. Este tipo de predicados es el único que entraría dentro de la noción de afectación de Tenny y estaría representado por predicados como pintar la valla o destruir el coche. El segundo grado de afectación se corresponde con aquellos predicados que implican un cambio de estado, pero no cuantificado. Este tipo de predicados, a diferencia del primero, ya no implica telicidad y engloba, por ejemplo, casos como calentar la leche o ensanchar la calle. Los predicados que integran el tercer grado de afectación, por oposición a los dos primeros, no implican ningún cambio de estado, pero sí dejan abierta la posibilidad de que este se produzca; $y$, entre los predicados pertenecientes a este tipo, se pueden mencionar como ejemplos golpear la mesa o restregar la mancha. Finalmente, el cuarto tipo de predicados, los que se insertarían en el último punto de la escala, serían aquellos de cuyo significado léxico no se desprende ningún tipo de cambio o efecto en el objeto, por ejemplo, observar un cuadro u oler un perfume.

El concepto de afectación que se desprende del trabajo de Beavers es, como se ha visto, bastante más amplio que el de Tenny, pues, además de los cambios cuantificados, como el representado por (48a), es capaz de explicar también la afectación que implican los verbos en objetos no cuantificados, tales como el de (48b); e incluso la afectación que pueden llegar a experimentar los objetos cuyo cambio explícito no está implicado por el propio verbo, sino tan solo de forma potencial, como es el caso de (48c). No obstante, quedaría aún sin explicar la afectación que intuitivamente se supone que experimentan objetos como al agente de policía, en (48d), o al carpintero, en (48e).

(48) Objetos afectados

a. El león despedazó a la cebra.

b. Luis calentó la leche.

c. María golpeó el cristal.

d. Ismael llamó al agente de policía.

e. La sierra cortó el dedo al carpintero.

En definitiva, Beavers considera solamente como afectados todos aquellos objetos que puedan experimentar un cambio de estado físico implicado por la propia semántica léxica del verbo; sin embargo, los objetos directos de verbos cuyo efecto es de carácter psicológico, como es el caso de (48d), prefiere mantenerlos al margen. Sostiene el autor que los verbos que introducen este tipo de objetos realmente no implican cambio observable alguno, sino que los hablantes son quienes los deducen de manera pragmática atendiendo a su conocimiento del mundo. Esto mismo lo aplica 
a los objetos indirectos, ya no solo en casos como el de (48e), sino también en aquellos como los de los verbos de posesión causada, del tipo de dar o enviar. En ellos el objeto directo pasa de estar en el dominio del Agente a formar parte del dominio del Destinatario o Beneficiario, por lo que este último pasa de no tener algo a poseerlo. No obstante, Beavers defiende que el único cambio del que se podría hablar sería el posible cambio psicológico que supondría el evento de transferencia y que, como ya se ha dicho, habría de ser inferido de forma pragmática, no de forma directa a partir de la semántica léxica del verbo. A pesar de todo, el autor reconoce que, en estos casos que se acaban de mencionar, se podría hablar de afectación en un sentido más amplio del que el contempla en sus trabajos; ${ }^{13}$ y este sentido más amplio es precisamente el que pretende recoger el segundo de los enfoques acerca de la noción de afectación.

La segunda perspectiva desde la que ha sido tenida en cuenta la afectación se asienta fundamentalmente en los trabajos de Jackendoff (1990) y Croft (1991; 2002), que a su vez parten ambos del modelo cognitivo basado en la dinámica de fuerzas de Talmy (1976). Este modelo recurre al concepto de fuerza como componente básico para la descripción semántica de los eventos. La fuerza es una noción física que posee una magnitud y que se transmite en una determinada dirección. Así pues, atendiendo a la semántica léxica del verbo, cada uno de los participantes en el evento adquiere una determinada fuerza que proyecta en una determinada dirección, de tal forma que los eventos quedan conceptualizados a grandes rasgos como una transferencia de fuerzas.

El participante que presenta una magnitud mayor de fuerza proyecta dicha fuerza hacia el resto de participantes, quedando estos afectados de distinta forma, atendiendo al papel que desempeñan en el evento. Para observar algún ejemplo de cómo se conceptualiza un evento basado en estos términos, se puede recurrir a los que se ofrecen en (49). En el primer caso, el evento consta de dos participantes, el Actor o Proto-agente y el Tema o Proto-paciente. Puesto que la energía que los participantes presentan en cada evento está directamente relacionada con el papel temático que desempeñan y, por tanto, con sus características proto-agentivas, en este caso, es evidente que es Juan el que más energía presenta y el que la proyecta entonces sobre el otro argumento del evento, en este caso el coche; provocando que este pase de estar parado a estar en funcionamiento. En lo que respecta a (49b), en este caso se trata de un evento con tres participantes: el Actor/Proto-agente, el Tema/Proto-paciente y el Destinatario/Proto-receptor. Así pues, María, que es la que más energía presenta en este caso, la proyecta sobre los otros dos participantes generando una «cadena causal» en la que cada parti-

13 Nota 18 a pie de página en Beavers $(2010,19)$. 
cipante, por la función que desempeña, queda afectado de una manera distinta: el regalo, recibe la energía directa de María, que provoca su desplazamiento entre dos dominios (el suyo propio y el del Destinatario); y, en segundo lugar, su hija queda afectada indirectamente en el sentido de que entra en su dominio de posesión un elemento que antes no lo estaba y pasa, por lo tanto, de carecer de ese elemento a poseerlo.

(49) Eventos de dos y tres participantes

a. Juan arrancó el coche.

b. María dio un regalo a su hija.

Lo interesante de este modelo es que relaciona directamente la afectación con la cualidad de «ser receptor de una fuerza», de hecho, en los eventos que suponen una transferencia de fuerza, el ser un participante afectado supone simplemente formar parte del evento, pero no ser su iniciador. Así pues, por oposición al enfoque espacio-temporal, el modelo basado en la dinámica de fuerzas no está basado en la noción de cambio, lo que permite explicar sin problema no solo la afectación de los objetos «potencialmente afectados», en términos de Beavers, sino también la afectación de otra serie de argumentos con papeles temáticos como los de Destinatario, Experimentante o Beneficiario/Maleficiario entre otros.

Para capturar la propiedad de objeto afectado Jackendoff propone la prueba que aparece representada en (50). Atendiendo a dicha prueba, se consideran afectados aquellos SN con la capacidad de aparecer en el siguiente marco sin que la estructura resulte anómala.

(50) Prueba de afectación (Jackendoff 1990, 125)

$\left\{\begin{array}{c}\text { Lo que le ocurrió } \\ \text { Lo que x le hizo }\end{array}\right\}$ a SN fue...

Beavers $(2011,339)$ reconoce que esta es quizá la única prueba específica que ha sido propuesta para poner a prueba la afectación. En términos de este autor, los objetos que son capaces de pasar de manera satisfactoria la prueba conforman un conjunto integrado por los tres niveles de su escala que implican algún grado de afectación, es decir, los predicados de cambio cuantificado, los de cambio no cuantificado y los de cambio potencial. Las oraciones de (51a), (51b) y (51c) sirven de ejemplo respecto a cada uno de los tres tipos de predicado mencionados. 
(51) Prueba de afectación aplicada a los distintos tipos de predicados

a. Juan destrozó la silla. > Lo que le ocurrió a la silla fue que Juan la destrozó.

$>$ Lo que Juan le hizo a la silla fue destrozarla.

b. María calentó la leche. > Lo que le ocurrió a la leche fue que María la calentó.

> Lo que María le hizo a la leche fue calentarla.

c. El niño golpeó el cristal.

$>$ Lo que le ocurrió al cristal fue que el niño lo golpeó.

> Lo que el niño le hizo al cristal fue golpearlo.

d. Luis increpó al trabajador.

$>$ Lo que le ocurrió al trabajador fue que Luis lo increpó.

> Lo que Luis le hizo al trabajador fue increparlo.

e. Ana envió un regalo a > Lo que le ocurrió a Carlos fue que Ana le Carlos. envió un regalo.

> Lo que Ana le hizo a Carlos fue enviarle un regalo.

f. La máquina cortó una mano al carpintero.

> Lo que le ocurrió al carpintero fue que la máquina le cortó una mano.

> Lo que la máquina le hizo al carpintero fue cortarle una mano.

Lo que se puede observar en estos ejemplos es que, más allá de los predicados que implican un cambio físico, la prueba parece aceptar también otra serie de formas de «quedar afectado». Este sería el caso de (51d) en el que el verbo increpar no implica directamente un cambio psicológico en el Experimentante, pero dicho cambio, o la generación de una reacción psicológica, se puede presuponer de manera pragmática, basándonos en nuestro conocimiento del mundo; así pues, la posibilidad de dicha presuposición hace posible que el enunciado no ofrezca resistencia semántica a la prueba de Jackendoff.

Por otro lado, en los ejemplos de (51e) y (51f), lo que se ha puesto en tela de juicio es la afectación del objeto indirecto. En ambos casos ocurre lo que en (51d), que, aunque el verbo en sí no implique la afectación directa de los participantes en cuestión, sí se puede presuponer algún tipo de afectación indirecta en ellos. Dicho cambio es producto del que sufren los argumentos con el papel de Tema y la relación que estos mantienen con sus respectivos objetos indirectos. En (51e), el indirecto presenta el papel de Destinatario, con lo cual el Tema entra en su dominio de posesión; mientras que en (51f), la afectación del objeto indirecto es si cabe más 
evidente, pues en este caso desempeña el papel de Experimentante y el evento implica la pérdida de una de sus extremidades de la que era poseedor inalienable.

Por todo lo anteriormente expuesto, el enfoque que esta investigación ha adoptado en los siguientes capítulos para abordar el concepto de afectación es el basado en la noción de dinámica de fuerzas. Como se ha demostrado, este permite dar explicación al comportamiento semántico de determinados argumentos, que parece estar relacionado con la afectación, pero escapa, sin embargo, al concepto más rígido que solo contempla la implicación del cambio físico de estado. Asimismo, la prueba que ha sido utilizada, de aquí en adelante, para evaluar la afectación de los objetos es la propuesta por Jackendoff $(1990,125)$, recogida anteriormente en (50).

En esta misma línea, los trabajos que también han tratado la afectación en un sentido parecido son todos aquellos relacionados con la noción de transitividad. Si bien es cierto que no hacen referencia al modelo de dinámica de fuerzas, sus propuestas reflejan una concepción de lo más similar a la que resulta de dicho modelo. Hopper/Thompson (1980, 251) definen la transitividad como una propiedad oracional que describe el grado en que una actividad es transferida de un agente a un paciente. Obsérvese el paralelismo con el enfoque antes presentado desde la misma definición, que parte del concepto de transferencia.

Hopper/Thompson (1980), con el objetivo de superar la vaguedad de la definición tradicional de transitividad, proponen el listado de factores recogido en la Tabla 2.2, en el que recogen aquellas propiedades que participan en la construcción del grado de transitividad de una oración.

Tabla 2.2: Factores que constituyen el grado de transitividad según Hopper/Thompson (1980, 252).

\begin{tabular}{lll}
\hline & \multicolumn{2}{c}{ GRADo DE TRANSITIVIDAD } \\
\cline { 2 - 3 } & Alto & Bajo \\
\hline Participantes & 2 o más participantes, A y 0 & 1 participante \\
\hline Kinesis & acción & no-acción \\
\hline Aspecto & télico & atélico \\
\hline Puntualidad & puntual & no puntual \\
\hline Volicionalidad & volicional & no volicional \\
\hline Afirmación & afirmativo & negativo \\
\hline Modo & realis & irrealis \\
\hline Agentividad & A con alta agentividad & A con baja agentividad \\
\hline Afectación del 0 & O totalmente afectado & O no afectado \\
\hline Individuación del O & O altamente individuado & O no individuado \\
\hline
\end{tabular}


Esta propuesta incluye un total de diez factores que involucran distintos aspectos de la efectividad o intensidad en que la acción descrita por el verbo se transmite de un participante a otro; sin embargo, tan solo los dos últimos factores son los que hacen referencia específica a las características del objeto. Entre ellos, precisamente, señalan los autores la afectación del objeto, sosteniendo que cuanto mayor sea esta, más alto será el grado de transitividad o la eficiencia con que quede transmitida la acción de un participante a otro y, como ejemplo, proponen el que aparece en (52).

(52) Afectación y transitividad (Hopper/Thompson 1980, 253)

a. Me bebí la leche.

b. Bebí un poco de la leche.

A pesar de la independencia de los factores señalados en la Tabla 2.2, algunos de ellos tienden a aparecer asociados y este es el caso, por ejemplo, de los dos factores referidos a las características del objeto. Así, según Hopper/Thompson, cuanto más individuado se encuentra un objeto, mejor se transfiere la acción a él y mayor es el grado en que puede quedar afectado; por lo tanto, bajo las mismas condiciones, un objeto definido se percibe normalmente como más afectado que uno indefinido, como ocurre al contrastar (53a) y (53b); o un objeto humano se percibe, igualmente, como más afectado que uno inanimado, tal como se observa de la comparación entre (53c) y (53d).

(53) Interacción entre afectación e individuación

a. Luis se bebió la cerveza.

b. Luis bebió cerveza.

c. Luis golpeó a Carlos.

d. Luis golpeó la mesa.

Asimismo, estos autores reconocen la conexión entre aspecto léxico y afectación señalando que la telicidad va unida a un elevado grado de afectación, mientras que la atelicidad implica un grado de afectación inferior y, para ello, recurren a ejemplos del finés como los que ya se presentaban en (41) y que aparecen recogidos de nuevo ahora en (54). La distinción entre acusativo y partitivo en finés sirve para codificar el aspecto léxico del predicado y, mientras que el partitivo asigna al predicado un valor atélico en el que el objeto no se ve afectado completamente, caso de (54a), el acusativo conduce a una lectura télica del evento que sí implica la afectación completa del objeto, que es lo que ocurre en (54b). 
(54) Interacción entre afectación y telicidad (Kiparsky 1998, 266)
a. Ammu-i-n karhu-a.
disparar-PST-1SG oso-PART
'Disparé al/a un oso.'
b. Ammu-i-n karhu-n.
disparar-PST-1SG oso-ACC
'Disparé al/a un oso (y lo maté).'

Esta distinción que se menciona a propósito del ejemplo de (54) entre totalidad/ parcialidad, en lo que a la afectación del objeto se refiere, se ha aplicado con frecuencia para explicar las diferentes realizaciones argumentales que puede presentar el objeto afectado en las distintas lenguas, donde generalmente se relaciona el caso acusativo con un grado de afectación total, mientras que se recurre al uso de casos oblicuos para codificar la afectación parcial del objeto. En los ejemplos de (55) se observa con claridad cómo en el primero de los casos se supone la afectación total de la pared, mientras que, en el segundo, la pared parece quedar afectada tan solo de manera parcial.

(55) Objetos totalmente/parcialmente afectados

a. Rociamos la pared con pintura.

b. Rociamos pintura sobre la pared.

En relación con la realización morfológica de los distintos grados de afectación, hay que destacar el trabajo de Tsunoda (1985; 1999). Este trabajo defiende en su conjunto la propuesta de Hopper/Thompson, pero considera necesaria una profundización en determinados aspectos de esta que, según su opinión, quedan desatendidos o planteados con demasiada ambigüedad. Entre dichos aspectos, el autor apunta a que la independencia entre los factores que recogen Hopper/ Thompson no es tal, pues algunos de ellos guardan entre sí una relación mucho más estrecha que otros; además, no todos los factores presentan la misma relevancia para explicar el fenómeno de la transitividad en cada una de las áreas de estudio de la gramática, sino que es posible demostrar que algunos de ellos son imprescindibles, como es el caso de la afectación, mientras que otros parecen presentar un papel mucho más secundario o, incluso, irrelevante en algunos niveles; $y$, respecto a la afectación, establece Tsunoda la necesidad de que sea descrita con mayor profundidad, pues las diferentes realizaciones argumentales de los objetos afectados dan pie a defender una gradación del factor que no queda clara, ni explícitamente justificada en el trabajo de Hopper/Thompson. Bajo estas premisas, el autor desarrolla una escala de afectación que establece la creación de nueve grupos de verbos, cuya formación atiende tanto a la semántica 
de dichos verbos como a los patrones de marcado de caso que presentan (Tabla 2.3). Los grupos situados en la parte superior de la escala son aquellos cuyos objetos presentarían un mayor grado de afectación y este iría disminuyendo según el grupo se encuentra más cercano al extremo inferior.

Tabla 2.3: Escala de afectación (Tsunoda 1985, 388).

\begin{tabular}{llll}
\hline 1 & Efecto directo en el paciente & $1 \mathrm{~A}$ & Resultativo \\
\cline { 3 - 4 } & & $\mathrm{B}$ B & No resultativo \\
\cline { 2 - 3 } 2 & Percepción & $2 \mathrm{~A}$ & Paciente más implicado \\
\hline 3 & Búsqueda & Paciente menos implicado \\
\hline 4 & Conocimiento & \\
\hline 5 & Sensación & \\
\hline 6 & Relación & \\
\hline 7 & Habilidad & \\
\hline
\end{tabular}

En línea con esta teoría, Blume (1998) estudia las estructuras con dos argumentos que presentan la siguiente estructura de caso: NOM-DAT/ABS-DAT. Estas estructuras representan las categorías situadas en el extremo inferior de la escala de Tsunoda y, precisamente, Blume sostiene que en ellas el nivel de transitividad es más bajo que en los casos de NOM-ACUS/ERG-ABS. La autora defiende que esto es debido a que el papel temático que reciben los argumentos no presenta la suficiente asimetría Agente-Paciente, es decir, que ambos argumentos presentan un número similar de características proto-agentivas; 0 , visto desde la perspectiva de la afectación, ninguno de los participantes resulta afectado físicamente o manipulado de forma directa por el otro participante, por lo que la afectación del argumento es menor (aunque no inexistente).

Y continuando con los estudios que han apuntado un estatus especial para el factor de la afectación en cuanto a la definición de la transitividad, se puede mencionar, asimismo, el trabajo de Testelec (1998). Este autor, a diferencia de Hopper/Thompson, reduce el número de factores a lo que denomina «dos parámetros básicos», que rigen la distribución de los distintos grados de transitividad: el control por parte del Agente y la afectación del Paciente; y, partiendo de ambos, defiende que «cuanto menor sea la similitud entre los dos participantes principales del predicado en términos de control y afectación, mayor será la transitividad semántica del verbo» (Testelec 1998, 41).

Por último, de entre los trabajos que han estudiado la transitividad y han destacado el papel fundamental de la afectación, es importante subrayar las apor- 
taciones de Næss (2004; 2007). Partiendo de la teoría de los prototipos (Rosch 1978; Lakoff 1987; Taylor 1995), Næss propone definir una construcción prototípicamente transitiva como aquella que describe un evento en el que intervienen dos participantes que son semánticamente distintos en la mayor medida posible en cuanto al papel que desempeñan en el evento descrito por la oración (2007, 30). Los papeles que desempeñen dichos participantes habrán de ser los de Agente y Paciente. Estos se conciben como nociones relacionales, es decir, que nacen de la relación que un elemento guarda con el resto de componentes de la oración; por lo tanto, no pueden definirse atendiendo a las propiedades intrínsecas de los SN, sino a las propiedades relacionales que el argumento en cuestión exhibe en el contexto que ocupa. A este fin, Næss defiende la existencia de tres propiedades relacionales mediante las cuales se definen los papeles de Agente y Paciente en las estructuras transitivas: (i) volicionalidad o intencionalidad, (ii) instigación y (iii) afectación. La presencia de las dos primeras define el papel de agente, mientras la tercera sería la que definiría el de paciente; por lo tanto, en términos de presencia o ausencia de las tres características mencionadas, los papeles temáticos fundamentales para describir una estructura prototípicamente transitiva quedarían definidos como se muestra en (56).

(56) Agente y paciente como categorías máximamente distintas (Næss 2007, 44)

a. Agente: [+VOL, +INST, $-\mathrm{AF}]$

b. Paciente: $[-\mathrm{VOL},-\mathrm{INST},+\mathrm{AF}]$

Los tres rasgos relacionales descritos por Næss, además de definir los papeles que constituyen la estructura transitiva prototípica, pueden aparecer en todas las combinaciones posibles dando lugar a distintos tipos de participantes como el de agente afectado [+VOL, +INST, +AF], experimentante volicional [+VOL, -INST, +AF], fuerza [-VOL, +INST, $-\mathrm{AF}]$ o instrumento [-VOL, +INST, $+\mathrm{AF}]$, que conducen a la formación de estructuras que se apartan en mayor o menor medida del prototipo transitivo. Como se puede apreciar, de este enfoque también se desprende que la afectación no es un rasgo que puede relacionarse tan solo con el objeto directo, sino también con el resto de argumentos.

Es importante añadir que el hecho de que las propiedades relevantes para definir la transitividad sean de naturaleza relacional hace que estén condicionadas o inducidas por las propiedades inherentes de los argumentos que las presentan. Así, la relación más evidente es quizá la que existe entre animacidad y volicionalidad, pues las entidades inanimadas, bajo cirsunctancias normales, no pueden ocupar posiciones en las que sea posible un individuo volicional. En lo que respecta a la afectación, la relación con las propiedades inherentes de los SN es algo más compleja. En primer lugar, Næss destaca el carácter subjetivo del con- 
cepto de la afectación, pues, atendiendo a la noción que ella maneja, la codificación lingüística de este rasgo depende de la percepción que tengan los hablantes de la entidad en cuestión, como más o menos afectada (2007, 111); sin embargo, sí que es cierto que esta percepción parece estar condicionada, generalmente, por los distintos rasgos que presente el SN. A este respecto, la definitud da pie a que la interpretación que se obtenga acerca de la afectación de un determinado objeto sea total o parcial, tal como ya mencionaban Hopper/Thompson (1980, 253). La interpretación en el caso de (57a) afecta a toda la leche que había disponible, mientras que en (57b) parece que tan solo parte de la leche disponible quedó afetcada.

(57) Afectación y definitud

a. Me bebí la leche.

b. Bebí un poco de leche.

En lo que concierne a las propiedades referenciales del SN, la especificidad resulta fundamental respecto al posible grado de afectación, puesto que los objetos hipotéticos o no existentes es imposible que puedan quedar afectados, es decir, que si un SN con función de objeto no hace referencia a una entidad específica, no hay manera de observar ningún tipo de efecto de la acción sobre dicha entidad; por lo que la referencialidad/especificidad se convertiría en un prerrequisito para la afectación.

Por último, en lo que a la animacidad respecta, Næss sigue a Mithun (1999) y defiende que los objetos animados, concretamente los humanos, son percibidos potencialmente como más afectados. Esto se debe a que las personas en su uso de la lengua, como ya señalaba Dahl $(2008,143)$, tienden a reflejar en los sistemas lingüísticos una perspectiva egocéntrica que sitúa la actividad humana en el centro de sus inquietudes; lo que conduce a concebir los posibles efectos que puedan resultar de la acción verbal como más relevantes en el caso de los objetos humanos que en el de los animados no humanos y, a su vez, más relevantes en el caso de estos últimos que en el de los objetos inanimados.

\subsubsection{Afectación y MDO}

Una vez presentados a grandes rasgos los distintos enfoques que han abordado la noción de afectación, el objetivo de este último subapartado es el de recopilar las ideas que han aportado las distintas perspectivas acerca de cuál es su influencia en el MDO. Algunos de los trabajos que han apuntado con mayor determinación en este sentido han sido aquellos que han equiparado la telicidad del evento con la completa afectación del objeto en cuestión. Uno de los ejemplos quizá más 
repetidos es el caso del finés, que ya aparecía en (41) y que se reproduce de nuevo en (58) por conveniencia. En dicha lengua, existen determinados verbos que ofrecen dos posibilidades de codificar su argumento interno y estas posibilidades son el caso partitivo y el acusativo. Mientras que la lectura que se obtiene del primero es la de un evento atélico no resultativo (58a), en el que el objeto no tiene por qué quedar afectado, el acusativo, por su parte, implica la afectación total del objeto, en este caso del oso, y la lectura que se obtiene del evento es, por tanto, télica (58b).

(58) MDO en finés (Kiparsky 1998, 266)
a. Ammu-i-n karhu-a.
disparar-PST-1SG oso-PART
'Disparé al/a un oso.'
b. Ammu-i-n karhu-n.
disparar-PST-1SG oso-ACC
'Disparé al/a un oso (y lo maté).'

Sin embargo, como ya se ha mencionado en el apartado 2.2.7.1, han sido numerosos los autores que, a pesar de reconocer la estrecha relación entre telicidad y afectación, han desligado ambos conceptos; y, precisamente, en esta línea argumenta Torrego sobre el español. Dicha autora, si bien reconoce que es frecuente que ambos factores aparezcan solapados actuando sobre un mismo objeto, sostiene que es posible encontrar ejemplos en los que se puede demostrar el efecto de la afectación independientemente del factor de la telicidad $(1999,1791)$. En lo que concierne a los objetos directos afectados, Torrego defiende que, en caso de ser animados, han de aparecer obligatoriamente acompañados de la marca preposicional y para ilustrar este hecho y, al mismo tiempo, desligar la afectación de la telicidad, la autora recurre a los ejemplos presentados en (59). Partiendo de que tanto ver como golpear son considerados verbos atélicos, Torrego atribuye la obligatoriedad del MDO en el objeto del segundo al factor de la afectación.

(59) Afectación y MDO en español (Torrego 2002, 58)

a. El guardia vio (a) un prisionero.

b. El guardia golpeó ${ }^{*}($ a) un prisionero.

No obstante, la autora reconoce que afectación y telicidad suelen aparecer solapadas y explica este hecho atendiendo a la posición coincidente que ocupan en la estructura sintáctica los objetos cuando resultan afectados y cuando forman parte de un predicado télico. 
Sin embargo, Torrego no ha sido la primera ni la única en señalar el impacto de la afectación en el uso de la marca preposicional en español. A comienzos del siglo pasado, Spitzer (1928) ya reconocía el carácter afectado que recibían los objetos acompañados de MDO tanto en español como en rumano. Asimismo, Pottier (1968) señala que el fenómeno del marcado preposicional en español no puede explicarse tan solo mediante las características que atañen al SN con función de objeto, sino que es necesario atender también al significado del verbo y ver qué relación se establece entre los argumentos externo e interno y en qué medida se transmite la acción denotada del agente al paciente o lo que él denomina grado de eficiencia $(1968,87)$. Dicho grado, según Pottier, es un rasgo que poseen los verbos, que se define atendiendo al nivel en que sus objetos quedan afectados y da pie a la construcción de la escala de afectación presentada en (60).

(60) Escala de afectación (Pottier 1968, 87)

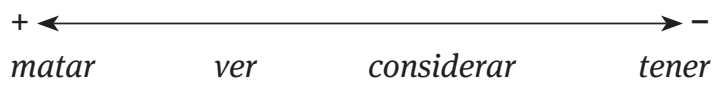

Nuevamente, observamos como también el enfoque propuesto por Pottier se sustenta sobre el concepto de transferencia y el hecho de que dicha transferencia se produzca es lo que da lugar a la afectación del objeto.

Tomando como referencia esta escala, von Heusinger (2008) y von Heusinger/Kaiser (2007) investigan el impacto de la semántica léxica de los verbos en el MDO en español a lo largo de la evolución del fenómeno. Para ello, parten de la consideración de que los verbos situados más a la izquierda en la escala de Pottier se corresponden con aquellos que seleccionan objetos humanos con mayor frecuencia, mientras que, en el extremo opuesto de la escala, ocurre precisamente lo contrario. Concluyen los autores que las clases léxicas de verbos establecidas a partir de la escala de Pottier influyen de manera evidente en el MDO a lo largo de toda su evolución (véase capítulo 3 para un análisis más amplio). Asimismo, von Heusinger/Kaiser (2011) abordan nuevamente el impacto de la afectación en el MDO del español, esta vez basándose en la escala de afectación de Tsunoda (1985) (véase Tabla 2.3). Los resultados de este segundo estudio arrojan algo de luz sobre el tema al confirmar que, en general, las clases léxicas de verbos establecidas por Tsunoda se corresponden con un mayor uso del MDO en el caso de los verbos que implican afectación, y un menor uso en el caso opuesto; pero apuntan también a desviaciones en el comportamiento de determinadas clases, como la de los verbos de sensación, con los que se espera una aparición relativamente escasa del marcador y, sin embargo, los resultados apuntan en la dirección opuesta. En el capítulo 3 se lleva a cabo un análisis más extenso de este trabajo debido al carácter diacrónico que lo define. Por todo ello, se podría concluir afir- 
mando que la afectación, a pesar de la falta de unanimidad en lo que a su definición respecta, es un factor que determina en mayor o menor medida la aparición del MDO en diversas lenguas, entre las que encontraríamos el español.

No obstante, el hecho de recurrir a la afectación para explicar el MDO no constituye una propuesta exenta de polémica. De Hoop (2015) representa quizá una de las críticas más directas al uso de la afectación para explicar el MDO; sin embargo, su crítica parece ir dirigida a la pretensión de explicar por medio de este factor la totalidad de los casos en que aparece el marcador, pues parece evidente, como expone la autora, que ante dos oraciones como las de (61), el factor que está interviniendo no es la afectación del objeto sino su definitud/especificidad.

(61) MDO en Hindi (Mohanan 1994, 80)

a. ilaa-ne haar uthaaya.

Ila-ERG collar.NOM levantar-PERF

'Ila levantó un collar.'

b. ilaa-ne haar-ko uthaayaa.

Ila-ERG collar-Acc levantar-PERF

'Ila levantó un collar.'

De forma similar a lo que ocurre con el ejemplo anterior, de Hoop propone una serie de ejemplos cuya explicación depende de otros factores distintos a la afectación y cuyo impacto no ha dejado de reconocerse nunca en la bibliografía.

La propuesta que la autora presenta pasa por sustituir la noción de afectación por la de prominencia, entendida como una cualidad que adquiere el SN debido, no solo a sus características intrínsecas, sino también a factores como la topicalidad o el orden oracional. Según la autora, esta noción más amplia y abarcadora recoge de manera más adecuada que el concepto de afectación la explicación de los distintos ejemplos que se muestran como argumentos a lo largo del trabajo. No obstante, lo que de Hoop no parece contemplar es que afectación y prominencia no sean conceptos excluyentes, es decir, que el de prominencia pueda englobar al de afectación como uno de los factores que contribuyen a su construcción y, precisamente, esta es la línea que se explora más en detalle en el capítulo 6 a la luz de los resultados de los dos estudios llevados a cabo en esta investigación.

\subsection{Funciones del MDO}

Hasta el momento, el objetivo de este capítulo ha sido simplemente el de presentar los diferentes factores que influyen en el MDO; sin embargo, llegados a este punto, cabe preguntarse por qué son estos factores y no otros los que interactúan, 
dando lugar al marcado. La respuesta a esta pregunta pasa por investigar cuál es la función que desempeña el MDO y, por lo tanto, atendiendo a dicha función, debería quedar explicada la motivación de los distintos factores. Ante esta última cuestión han surgido fundamentalmente dos grandes corrientes que apuntan a las dos funciones que se le atribuyen al marcado: la función diferenciadora (o desambiguadora) y la función codificadora (o indexadora).

El propósito de este apartado es el de recoger las principales ideas que se han postulado en la bibliografía para respaldar cada una de las posturas mencionadas; y, a partir de ello, reflexionar sobre la forma en la que encajan los distintos factores vistos hasta el momento en la justificación de ambas funciones y sopesar cuál de las dos funciones presenta el MDO en español o en qué medida pueden coexistir las dos.

\subsubsection{Función diferenciadora o desambiguadora}

La necesidad de distinguir qué función desempeña cada uno de los argumentos que componen una oración es común a todas las lenguas naturales y para afrontar dicha necesidad las lenguas recurren al marcado de caso; sin embargo, no todas ellas implementan el marcado de caso de la misma forma, sino que son varias las posibilidades que existen de hacerlo: el orden oracional, la morfología flexiva o el uso de adposición (bien sea preposición o postposición). No obstante, las lenguas son sistemas que se encuentran en continuo desarrollo, entendido como continuo proceso de construcción, destrucción y reestructuración, y, como señala Bossong $(1991,144)$, los sistemas de marcado de caso no son una excepción y también desaparecen y, con su desaparición, otros mecanismos surgen para ocupar su función, pues, aunque el sistema se renueve, la necesidad de distinción entre los participantes de un evento permanece. El debilitamiento del sistema de casos latino fue, en el caso de las lenguas románicas, el hecho que provocó el surgimiento de nuevos sistemas de marcado de caso que viniesen a suplir la declinación morfológica y este, precisamente, habría sido el «caldo de cultivo» del que habría surgido el MDO actual.

La teoría que postula la necesidad de distinguir entre sujeto y objeto directo como función del marcado preposicional de objeto en las lenguas románicas, no solo como motivo de su aparición, sino como función que se ha mantenido hasta la actualidad, es la más antigua y la que más peso ha tenido en toda la tradición de estudios acerca del tema. En lo que se refiere al español, encontramos uno de los primeros testimonios de este planteamiento ya en El diálogo de la lengua de Juan de Valdés, obra escrita en el siglo XVI, a pesar de ser publicada en 1736. En ella, Valdés defiende que es necesario el uso de la preposición en determinados 
contextos con el siguiente argumento: «En este error caen especialmente los que quitan una a que se deve poner delante de algunos acusativos, y assí aviendo de dezir: «el varón prudente ama a la justicia» dizen «ama la justicia», la qual manera de hablar, como veis, puede tener dos entendiemientos, o que el varón prudente ame a la justicia, o que la justicia ame al varón prudente; porque sin la a parece que stan todos dos nombres en un mesmo caso» (Valdés 1535, 167).

Ya en el siglo xx, Lenz expresa la forma clásica de esta teoría de la siguiente manera: «el complemento directo lleva la proposición a si es lógicamente posible considerarlo como sujeto de la oración» $(1920,52)$. Explica el autor que los sujetos hacen referencia generalmente a personas y solo rara vez a objetos, por lo que surge la ambigüedad cuando tanto el sujeto como el objeto poseen un referente humano. Este razonamiento se ha mantenido casi intacto en la lingüística hispánica hasta finales del siglo pasado y, por ejemplo, Alarcos (1999, 278-279) lo recoge aún en su gramática de una manera casi exacta. No obstante, algunos autores han señalado que el hecho de atribuir al uso del MDO la mera función de evitar que se produzca la confusión entre sujeto y objeto presenta algunas debilidades. Estas se deben fundamentalmente al hecho de que, en muchos casos, las lenguas poseen ya otros mecanismos para evitar que dicha confusión se produzca. En (62) se presentan tres ejemplos del español, de los cuales tan solo en uno de ellos, el de (62c), la función de evitar la confusión entre sujeto y objeto podría alegarse como necesaria. El objeto directo de (62a) aparece con MDO; sin embargo, no se puede postular que su uso se deba a evitar la confusión entre los dos participantes del evento, pues la concordancia entre sujeto y verbo hace imposible en este caso otra interpretación diferente a aquella en la que los estudiantes ejercen la función de sujeto. En lo que respecta a (62b), es un ejemplo recuperado del anteriormente citado Diálogo de la lengua de Valdés, en el que el autor sostenía la necesidad de la marca preposicional para evitar la confusión; no obstante, el hecho de que el español sea una lengua que permite una relativa flexibilidad en el orden oracional, no implica que no exista un orden más frecuente (SVO) o no marcado (Leonetti 2014, 3). ${ }^{14}$ Así, a pesar de que gramaticalmente pueda obtenerse la confusión que alega Valdés, la interpretación no marcada y, por tanto, la más frecuente, sería aquella en que el varón ejerce la función de sujeto oracional, independientemente de la presencia o ausencia del MDO. Por ello, tan solo en el último caso (62c), donde ni la concordancia, ni el orden oracional contribuyen

14 Si bien es cierto que el orden no marcado en español es el de SVO, es interesante señalar que en Valdés influye el hecho de que en español antiguo y durante los Siglos de Oro era más frecuente que en la actualidad el orden OVS. 
a favorecer una interpretación u otra, podría admitirse la hipótesis del marcado preposicional como mecanismo para evitar la confusión.

(62) Mecanismos para evitar la confusión sujeto/objeto

a. Los estudiantes escucharon al profesor.

b. El varón prudente ama la justicia.

c. ${ }^{*}$ Persigue el padre el hijo.

Asimismo, el origen del marcado preposicional en las lenguas románicas no parece tampoco confirmar la teoría de que la función esencial del fenómeno sea la de evitar la ambigüedad entre sujeto y objeto, puesto que parece ser que la categoría con la que comenzó a aparecer la marca fueron los pronombres, que, precisamente, constituían la única categoría en la que se habían mantenido restos de la antigua declinación y, por lo tanto, no habría existido la necesidad de evitar la confusión (véase apartado 3.2).

Por todo lo expuesto, la teoría de la desambiguación, entendida literalmente como la necesidad de eliminar la ambigüedad entre sujeto y objeto, ha perdido relevancia pues su aplicación se reduciría a la explicación de un número muy escaso de casos excepcionales. No obstante, en las últimas décadas del siglo xx surgió una nueva interpretación a favor de la función diferenciadora del MDO que ha ido ganando peso y se ha mantenido hasta la actualidad. La propuesta surgió en el ámbito de la lingüística tipológico-funcional y fueron trabajos como los de Silverstein (1976) o Comrie (1979) los que sentaron sus bases.

Dicha propuesta se basa en el hecho de que, desde una perspectiva tipológica, la construcción transitiva más frecuente o «menos marcada» es aquella en la que la acción expresada por el verbo se transmite de un agente que posee un grado elevado de animacidad y definitud, a un paciente que, por oposición, presenta un escaso grado de estos dos rasgos; y cualquier desviación de esta distribución da pie a una estructura «más marcada» (Comrie 1989). La implicación de esta afirmación es, por tanto, que aquellas construcciones que resulten funcionalmente más marcadas también deberían serlo formalmente y, por ello, es esperable que las lenguas posean algún mecanismo especial para indicar que el agente presenta un grado escaso de animación o definitud o que el paciente muestra un elevado nivel de alguna de estas dos características. Como ejemplos, menciona Comrie, entre otros, el turco, cuyo morfema de acusativo aparece solo con los objetos específicos (véase apartado 2.2.3) o los casos del hindi y el español, donde el MDO viene dado tanto por la animacidad como por la definitud/especificidad (véanse apartados 2.2.1 y 2.2.2).

En resumen, el marcado de caso quedaría configurado desde este punto de vista por dos principios: (i) tan solo reciben la marca aquellas categorías menos 
frecuentes para una determinada función (principio de economía) y (ii) las categorías funcionalmente más marcadas, es decir, las menos frecuentes, son las que se espera que también sean las más marcadas formalmente (principio de iconicidad). Esta idea ha sido formalmente desarrollada por Aissen (2003) en uno de los trabajos que más ha influido en los estudios actuales sobre MDO.

Aissen parte de la generalización que se extrae de los estudios tipológicosfuncionales previos sintetizándola de la siguiente manera:

(63) Principio que rige el MDO (Aissen 2003, 436)

Cuanto mayor es la prominencia de un objeto directo, más probable es que este reciba marcado de caso de forma explícita.

Según la autora, el grado de prominencia se establece atendiendo a las escalas de animacidad y definitud/especificidad, que se presentan de nuevo ahora en (64) y (65).

(64) Escala de animacidad

humano $>$ animado $>$ inanimado

(65) Escala de definitud/especificidad

pronombres personales $>$ nombres propios $>$ SN definidos $>$ SN indefinidos específicos $>\mathrm{SN}$ indefinidos no específicos

Según su planteamiento, las dos funciones sintácticas de los dos argumentos principales, es decir, sujeto y objeto, se relacionan con las escalas de (64) y (65) de forma inversa, es decir, las características más comunes en el sujeto son las menos esperables en el objeto, y viceversa. Así pues, el grado de prominencia de un argumento está determinado por la medida en que este se aparta de los rasgos más comunes en su posición y, por lo tanto, un objeto se considera más prominente cuanto mayor sea la similitud que presenta respecto a los sujetos más comunes (Aissen 2003, 437). Por lo tanto, esta autora defiende que es importante superar la visión estricta de que la función del MDO es simplemente evitar la ambigüedad entre sujeto y objeto, en pro de un enfoque más amplio por el que son los propios rasgos del objeto los que determinan la posibilidad de marcado, rasgos, eso sí, motivados por la relación de inversión de marcado que existe entre sujeto y objeto.

El modelo de Aissen ha supuesto una formalización del enfoque que defendía la función diferenciadora del MDO, influyendo en numerosos estudios posteriores y provocando el surgimiento de un debate en el que se están revisando los patrones de diversas lenguas que parecen no encajar en el modelo, al menos en primera instancia. 


\subsubsection{Función codificadora o indexadora}

El enfoque que defiende la función codificadora o indexadora como principal motivación del MDO asume que la utilización de la marca está relacionada con la presencia de una serie de características en el objeto. A diferencia del enfoque expuesto en el apartado anterior, en este caso la marca no se asocia con la relación establecida entre los dos principales argumentos de una oración, sino únicamente con las características del propio objeto directo.

Esta teoría encuentra sus raíces en el estudio clásico de Hopper/Thompson (1980) en el que se concibe el MDO como una marca de alta transitividad, más que como una desviación del prototipo transitivo. El marcado de objeto, señalan los autores, coincide con otros rasgos que implican un alto grado de transitividad, como la telicidad, la afectación del objeto y, especialmente, con la individuación del propio objeto, teniendo en cuenta que esta se define en términos de animacidad y definitud fundamentalmente (1980, 255-256). Como ejemplos, acuden al MDO en español y en hindi, lenguas en las que el fenómeno está restringido, como ya se ha expuesto anteriormente, a los objetos humanos y referenciales en la primera de ellas y a los objetos definidos en la segunda. Además, en lo que a la individuación del objeto se refiere, defienden que la intuición de Comrie (1979) no es del todo acertada al afirmar que el tipo de objeto más natural se caracteriza por ser inanimado e indefinido y achacan esto a una interpretación indebida de los datos de Givón (1976). Según los autores, de dichos datos solo se puede extraer que, de haber un SN indefinido y/o inanimado en la oración, este tiende a desempeñar la función de objeto; sin embargo, esto no implica que la mayor parte de los objetos sean indefinidos y/o inanimados; asimismo, Comrie no tiene en cuenta si los objetos pertenecen al primer plano discursivo (foreground) o al trasfondo (background) y, según Hopper/Thompson, si se tienen en cuenta tan solo los objetos directos que se encuentran en primer plano, la tendencia que se observa es que estos presentan mayoritariamente rasgos de objeto altamente individuado, es decir, objetos definidos y humanos. Por todo ello, los objetos individuados tendrían que ser considerados más naturales que los indefinidos/ inanimados y, por tanto, los autores consideran que lo que realmente señala el MDO es la «condición de objeto» $\mathrm{y}$, de manera simultánea, la alta transitividad del conjunto de la oración (1980, 291).

Sin embargo, la idea de que los objetos directos son prototípicamente individuados no deja de ser conflictiva. García García $(2014,78)$ ofrece datos al respecto, a partir de una búsqueda de corpus sobre el español, y sostiene que el 90,1\% (48.231/53.548) de los casos encontrados de estructuras transitivas se corresponden con oraciones cuyo objeto directo es inanimado, frente al tan solo 9,9\% (5.317/53.548), en las que el objeto directo hace referencia a una entidad animada. 
Asimismo, Dahl/Fraurud $(1996,51)$ también llevan a cabo un estudio de corpus, en su caso sobre el sueco, y los resultados tampoco apuntan a la individuación como característica prototípica de los objetos, al menos en términos de animacidad: el 87\% (3.896/4.476) de los SN con función de objeto directo que encontraron poseían un referente inanimado, frente al 13\% (580/4.476), que poseía un referente animado.

En la línea de Hopper/Thompson, Næss (2007) lleva a cabo un trabajo en el que desarrolla el enfoque propuesto por estos autores y donde critica la contradicción con el modelo de transitividad que implican las propuestas de Comrie y Aissen. Como señala Næss, existen algunas lenguas en las que, si el argumento interno está integrado por un SN indefinido, este se codifica entonces como oblicuo y no como objeto directo; por lo tanto, el hecho de que los SN indefinidos den lugar a estructuras formalmente intransitivas paraece poner en entredicho la llamada "generalización de Comrie», de que los SN indefinidos y/o inanimados representan la clase más natural de objeto en las estructuras transitivas. De esta manera, desliga Næss el concepto de prototipicalidad del de frecuencia, al sostener que el hecho de que la mayor parte de los objetos directos sean inanimados, no implica que este tipo de objetos sean los que se corresponden con un mayor grado de transitividad.

La autora, como ya se apuntó anteriormente (véase subapartado 2.2.7.1), fundamenta entonces la noción de transitividad prototípica en su hipótesis de los argumentos máximamente distintos, que sostiene que la oración transitiva prototípica es aquella donde los dos participantes son máximamente distintos en cuanto a sus papeles en el evento descrito por la oración. Su concepto de máxima distinción semántica se basa, como veíamos, en diversos factores, pero el que define fundamentalmente al objeto/paciente es la afectación y, por lo tanto, los objetos afectados son los que se podrían considerar realmente como objetos prototípicos. No obstante, aunque según Næss, no se debe recurrir a las características intrínsecas del objeto para definir su papel temático, en su trabajo defiende que animacidad y definitud son dos rasgos estrechamente relacionados con la afectación, puesto que el grado de afectación del objeto es mayor cuanto mayor es su grado de individuación. Consecuentemente, en contra de lo que defendía el enfoque expuesto en el apartado anterior, los objetos funcionalmente marcados no son los que formalmente también lo están, sino todo lo contrario, son aquellos funcionalmente no marcados, es decir, prototípicos, los que recibirán algún tipo de marca formal.

Dalrymple/Nikolaeva $(2011,226)$ también han defendido la función codificadora o indexadora, pero desde un punto de vista diferente. Estas autoras argumentan que el MDO tiene lugar en aquellos objetos que desempeñan la función informativa de tópico secundario; así pues, el fenómeno del marcado no tendría 
lugar para diferenciar al objeto del sujeto, sino precisamente para señalar la presencia de rasgos que acercan el primero al segundo.

Diversos autores, entre los que se pueden citar de Hoop/Narasimhan (2005), Næss (2007) o Malchukov (2008), han señalado que, a pesar de la diferencia de planteamientos, el enfoque desambiguador y el codificador conducen, a grandes rasgos, a los mismos resultados en lo que respecta al MDO. Este hecho ha provocado que se haya apuntado la posibilidad de que ambos enfoques no sean excluyentes, sino que puedan presentar una distribución complementaria y actuar ambos sobre el marcado de algunas lenguas; de hecho, los sistemas de marcado de caso en los que se puede defender una función puramente desambiguadora parecen ser realmente escasos desde una perspectiva sincrónica (de Hoop/Narasimhan 2005; de Hoop/Malchukov 2008, 595). En esta línea, de Swart (2007) propone un modelo que contempla la interacción de los dos enfoques y defiende que en algunas lenguas actúan de manera complementaria las dos estrategias de marcado: una se utiliza cuando es necesario eliminar la ambigüedad entre sujeto y objeto y la otra, para marcar objetos que son prominentes (2007, 4-5). Esta situación sería precisamente la que, en el capítulo 6, se defiende para el español.

\subsection{Síntesis}

Este capítulo ha revisado, en primer lugar, las principales ideas que se han apuntado en la bibliografía previa acerca de los distintos factores que influyen en el MDO. El objetivo no era otro que el de intentar establecer de qué forma se relaciona cada uno de ellos con el marcado preposicional, especialmente, atendiendo a los datos del español. Además, esta revisión ha permitido comprobar la escasez de trabajos que han estudiado dicha relación en el caso de los factores de telicidad y afectación. Ante este hecho, se torna necesario, por lo tanto, continuar indagando acerca de la manera en que estos dos factores influyen en el MDO, intentando encontrar datos en los que sea posible sustentar las afirmaciones que algunos estudios previos han realizado acerca de su influencia.

No obstante, se ha podido comprobar que tanto la telicidad como la afectación son dos nociones que se han estudiado ampliamente desde multitud de enfoques diferentes. Por ello, ha sido necesario establecer en cada caso cuál es el enfoque que se ha adoptado a lo largo de los siguientes capítulos para definir cada uno de los dos factores; así como las pruebas que han sido elegidas para comprobar su incidencia en los diferentes enunciados.

Recapitulando, la telicidad se considera una propiedad del SV, que se constituye mediante la interacción de la clase aspectual del verbo, las propiedades del objeto directo y la posible intervención de adjuntos con función delimitadora; y 
la prueba gramatical que concierne a este factor es la presentada nuevamente en (66), que consiste en comprobar si un determinado predicado admite la adición de un SP con valor delimitador, encabezado por la preposición en.

(66) Prueba de telicidad (Vendler 1957, 145-146)

a. \#Pedro supo/conoció la respuesta (en dos minutos).

b. \#María corrió/empujó un carro (en dos minutos).

c. Luis corrió cincuenta metros/dibujó un circulo (en diez segundos).

d. Ana alcanzó la cima/ganó la carrera (en treinta minutos).

En lo que a la afectación respecta, en este trabajo se ha adoptado la definición basada en la noción de dinámica de fuerzas, mediante la que se equipara la condición de afectado con la de «ser receptor de una fuerza». La prueba utilizada para considerar la afectación de un determinado argumento es la que aparece, de nuevo, recogida en (67):

(67) Prueba de afectación (Jackendoff 1990, 125)

$$
\left\{\begin{array}{c}
\text { Lo que le ocurrió } \\
\text { Lo que x le hizo }
\end{array}\right\} \text { a SN fue... }
$$

Ambas definiciones, y sus respectivas pruebas, son las que han servido de punto de partida para los dos estudios empíricos realizados y presentados en los capítulos 4 y 5 .

En la segunda parte de este capítulo, se ha fijado el punto de mira en las diferentes teorías que existen acerca de la función que desempeña el MDO. En este caso, el objetivo era arrojar algo de luz sobre la relación que los distintos factores guardan entre sí, para llegar a entender por qué precisamente son los factores que se han mencionado en la primera parte los que acarrean el marcado y no otros.

La situación que ha quedado reflejada es que las dos funciones que han sido postuladas para explicar el MDO no parecen ser excluyentes y pueden coexistir ambas en una misma lengua; no obstante, el enfoque adoptado en este trabajo apunta en la dirección de que la función predominante del marcado parece ser la codificadora o indexadora, mientras que la diferenciadora estaría reducida, al menos en español, a contextos muy limitados. De todas formas, esta es una idea que será desarrollada con mayor amplitud en el capítulo 6, tras conocer hasta qué punto la telicidad y la afectación han demostrado ser relevantes para la explicación del MDO. 
La información aportada por este capítulo nos pone en disposición de afrontar la investigación sincrónica acerca de los dos factores en los que se centra este estudio. No obstante, para responder a la primera de las preguntas específicas que se planteaban en la introducción, es decir, acerca del origen y la evolución de la influencia de telicidad y afectación en el MDO, es necesario llevar a cabo un repaso de los trabajos diacrónicos que han abordado el tema. Esta será, por tanto, la finalidad del siguiente capítulo. 
